\title{
LOS ORÍGENES DE LA CONSTRUCCIÓN DISCURSIVA DEL TERRITORIO DE AISÉN POR PARTE DEL ESTADO DE CHILE (1818-1929)
}

BORIS A. ARAYA V.a

\section{RESUMEN ${ }^{1}$}

Este artículo tiene como tema de estudio la manera en que históricamente se ha relacionado el territorio de Aisén con el Estado nacional, analizando conjuntamente los orígenes de una representación discursiva particular que realizan las autoridades a cargo del país y que al mismo tiempo condicionaría su actuar respecto de esta zona. Es por ello que se plantea a modo de hipótesis que el Estado chileno realizaría tal representación discursiva en dos etapas fundamentales: una de ellas surgida a partir de las diversas expediciones hidrográficas y la información que estas entregan, desde inicios de la era republicana y hasta fines del siglo XIX, y una segunda etapa, marcado por la construcción y expansión de una representación discursiva sobre Aisén implícita en las acciones y dictámenes estatales, pudiéndose hablar de que el significado otorgado a Aisén y las características asignadas a él (en general negativas), se vuelven una constante histórica.

PALABRAS CLAVE: estado, Aisén, territorio, discurso.

\section{THE ORIGINS OF THE DISCURSIVE CONSTRUCTION OF THE AYSÉN TERRITORY BY THE STATE OF CHILE (1818-1929)}

\begin{abstract}
This article examines the historical relation between the territory of Aysen and the National government, analyzing both the origins of a particular discursive representation implemented by the authorities of the country and the way this would shape their actions in this zone. Based on this, we raise the hypothesis that the Chilean government would perform such discursive representation in two main stages: The first stage emerges from the various river expeditions and the information they provide since the beginning of the republican era and until the late nineteenth century; and the second stage is marked by the construction and expansion of a discursive representation on Aysén which is implicit in

a Alumno de doctorado en Historia, Instituto de Historia, Pontificia Universidad Católica de Valparaíso, Chile. boris_araya_v@yahoo.es

1 Este artículo fue elaborado a partir de la tesis magister en Historia, adscrita al proyecto Fondecyt Regular $\mathrm{N}^{\circ} 1120704$ y al grupo de estudios "Circulación de la información, objetos y personas", Instituto de Historia, Pontificia Universidad Católica de Valparaíso, Chile.
\end{abstract}


the state's actions and dictums. It can be said that the meaning given to Aysén -and the features assigned to it (usually negative) - become a historical constant.

KEY WORDS: state, Aysén, territory, discursive representation.

\section{INTRODUCCIÓN}

Las protestas sociales vividas en la región de Aisén del General Carlos Ibáñez del Campo durante el año 2012, la reposicionaron en la discusión nacional en torno al significado de habitar en lugares extremos y el rol que le cabe al Estado chileno en su desarrollo, al realzar una serie de problemáticas que deben de sobrellevar sus habitantes: aislamiento, encarecimiento de la vida y conectividad limitada con el resto del país, entre otras.

Las anteriores debilidades hunden sus raíces en el proceso histórico que llevó a esta zona a convertirse en un área diferenciada, adquiriendo una denominación y unos rasgos identitarios peculiares. Es por ello que centramos la mirada en la región de Aisén, entendiéndola no solo como una delimitación administrativa sino como un espacio con dinámicas culturales complejas, donde el Estado ha tenido un papel pasivo ${ }^{2}$. La anterior consideración resultadel estudio de la producción documental emanada desde las diversas autoridades nacionales desde los inicios de la era republicana y hasta 1929 aproximadamente, además de sus primeros exploradores, quienes aportaron con sus expediciones a aumentar (en teoría) el acervo de conocimientos sobre Aisén, surgiendo la pregunta respecto de la manera mediante la cual el Estado establece significados sobre lo que para él representa este territorio y cuál sería su gestación e implicancias.

Se plantea la existencia de un proceso de construcción discursiva mediante el cual el Estado chileno crea y otorga significados a esta zona, destacándose en él dos etapas fundamentales: A) la primera originada en las expediciones

2 El marco geográfico lo constituye no solo la región de Aysén del General Carlos Ibáñez del Campo (entre los 4338' y $49^{\circ} 16^{\prime}$ de latitud sur) y cuyos límites son Argentina hacia el este (y a la cual esta comunicada por varios pasos fronterizos) y los archipiélagos de los Chonos y de las Guaitecas por el poniente, sino que también comprende las tierras hidrográficas y la información que éstas entregan desde inicios de la era republicana y hasta fines del siglo XIX, y B) un segundo momento, marcado por la cristalización y expansión de una representación discursiva sobre Aisén implícita en las acciones y dictámenes estatales, pudiéndose hablar que el significado otorgado a Aisén y las características asignadas a él (en general negativas), se vuelven una constante histórica, influyendo al mismo tiempo en el propio actuar de los gobiernos nacionales.

Es por ello que toda su complejidad geográfica, conspiró, amén de otros factores, para que estas tierras permanecieran llenas de conjeturas sobre su real fisonomía desde la época colonial. La Trapananda era un término empleado en ocasiones durante el siglo XVI para referirse a ellas. Denominación que convivió con la de los Césares de la Patagonia, creencia que cobró fuerza durante las primeras décadas del siglo XVII, iniciándose con ello una serie de excursiones en su busca, lo que coincidió (y en ocasiones se yuxtapuso) con la penetración evangelizadora jesuita en los archipiélagos al sur de Chiloé. A ello se suma, desde finales del siglo XVII y todo el XVIII, el progresivo temor a la invasión inglesa, lo que acrecentará la necesidad de conocerla "científicamente", máxime si se toma en cuenta el naufragio de la fragata Wager, parte de una flota cuyo fin era precisamente, la toma de puntos estratégicos australes. En ese contexto se entienden las expediciones del P. José García, aunque su afán como misionero era principalmente la evangelización; y José de Moraleda y Montero piloto de la Real Armada. A éste último se le debe la identificación del estero con que más tarde se conocerá a toda la región: Aisén (Moraleda, 1888, p. 433), y que años antes el padre García había

\footnotetext{
ubicadas al norte del rio Palena y que esta investigación sitúa hasta el paralelo $41^{\circ}$ de latitud sur (seno del Reloncaví aproximadamente), dado que entre este último hito y el paralelo $49^{\circ}$ por el sur (zona de campos de hielo) se aprecia un desarrollo histórico semejante relativo a la manera en que el Estado chileno la ha ido concibiendo (Fig. 1).
} 
llamado Los Desamparados. ${ }^{3}$

A mediados del siglo XIX, dichas nomenclaturas genéricas van dando paso, en documentos oficiales, al de Patagonia Occidental ${ }^{4}$, en referencia a la zona continental frente a Chiloé y hasta el estrecho de Magallanes. Ello aún es indicador de que Aisén sigue siendo calificado sin mayor acotación, por lo que al iniciar el siglo XX, esta zona era escasamente conocida por el Estado, siendo las cuencas hidrográficas, los puntos de referencia más importantes ${ }^{5}$. De hecho la denominación "Aisén" se hace común recién hacia 1901, como lo demuestra una propuesta para instalar una línea de navegación por los canales australes, levantada por Guillermo Lagreze $^{6}$. No obstante, la masificación de dicho concepto comenzará en 1927 producto de la división político-administrativa que integró (en teoría) al país este territorio.

De esta manera, la existencia de una construcción discursiva de parte del Estado de Chile ${ }^{7}$ sobre Aisén, implica la presencia de un conjunto de ideas creadas y significadas socialmente en relación a las diversas características de esta zona, las que en su mayoría resultan negativas, por lo que se entenderá por discurso las prácticas sociales en las que se encuentran el uso del lenguaje (escrito y oral) existiendo una "relación dialéctica entre las practicas discursivas particulares y los ámbitos de acción específicos (lo que incluye las situaciones, los marcos institucionales, las estructuras sociales) en que se hallan ubicados" (Wodak, 2003a, p.

3 La historiadora Ximena Urbina se ha ocupado de estudiar, de manera muy completa y analítica, la historia del territorio de Aysén durante el período colonial, destacando la interacción entre indígenas llamados "canoeros", españoles e indígenas de Chiloé y navegantes ingleses, en las islas y costas entre las islas Guaitecas y el estrecho de Magallanes. Sus aportes históricos y metodológicos han sido fundamentales para el desarrollo de esta investigación. Entre sus numerosos artículos y capítulos de libros destacamos, Urbina (2014).

4 Documento Viaje de exploración de la Corbeta Chacabuco, $\mathrm{N}^{\circ}$ 16, 15 de diciembre de 1870. En Memoria que el Ministro de Estado en el Departamento de Marina presenta al Congreso Nacional de 1871 (1871). Santiago: Imprenta Nacional., p. 279.

5 Por ejemplo, en los decretos estatales de concesión de tierras a particulares a comienzos del siglo XX se concedían a José Cámpelo (Decreto № 12098 de octubre de 1902) y Luis Aguirre (Decreto $N^{\circ}$ 659, 19 de mayo de 1903), las tierras situadas entre los ríos Yelcho y Palena y los valles de Coihaique, Nirihuan y Mañihuales respectivamente. Archivo Nacional de la Administración. Min.RR.EE, Vol. 1.092.
104). Desde esa lógica el Estado chileno a lo largo del tiempo se ha convertido en un individuo ${ }^{8}$ que significa su propia experiencia (en este caso sobre Aisén), "y por sus actos de significar, la realidad social es creada, mantenida en buen orden y continuamente modelada (shaped) y modificada" (Lozano, Peña \& Abril, 1989, p. 40). La representación que el Estado realiza por medio de los documentos por éste producidos, se vuelven acciones simbólicas que actúan sobre el mundo y sobre los demás habitantes del país, por lo que al analizar la manera de actuar y de referirse a esta área, se tendría que la esquematización cognitiva y lingüística desprendida de ellas "operan con unas finalidades en cada discurso: orientar al otro hacia un sentido, hacia una cierta concepción del mundo" (Carrillo, 2006, p. 130). Las estructuras dominantes del poder central, productoras de saberes legales (leyes y decretos) y científicos (diarios, cartografía) y por ello de "sentido" para los chilenos y para sí mismos sobre todo, "estabilizan las convenciones y las convierten en algo natural" (Wodak, 2003b, p. 20), de una manera en que muchas veces no es explícita, sosteniéndose que las autoridades estatales sin darse cuenta y sin intencionalidad, en ocasiones, dejan entrever su concepción sobe la (in)utilidad de Aisén.

Cabe destacar que las fuentes utilizadas contribuyen al análisis respecto de la fijación del conocimiento geográfico sobre un área que hasta mediados del siglo XIX estaba en su mayor parte

6 Lagreze, G. (1901). Propuesta para establecer línea de navegación. Archivo Nacional de la Administración. Ministerio de Relaciones Exteriores, Culto y Colonización, Vol. 1.041.

7 Se entiende aquí que el Estado lo constituyen el conjunto de instituciones y autoridades, sobre todo el presidente de la República, sus ministros y congresistas, capaces de influir e impactar con sus decisiones la realidad de la zona que aquí se estudia. El criterio fundamental para la elección de esta definición, es la facultad que poseen estas instituciones y autoridades para ejercer algún tipo de "poder", es decir, que su voluntad sea aceptada y llevada a efecto en la práctica.

8 Se entiende aquí como sinónimo de sujeto colectivo, pues éste de manera supraindividual construye el "tejido discursivo", el cual termina por independizarse con el tiempo de los productores del mismo a consecuencia de los procesos históricos. Ello refuerza la idea de que ciertas características, formas de ver y actuar frente a Aysén se mantienen en el tiempo a pesar del cambio de actores y las transformaciones propias de la sociedad chilena. (Jäger, 2003, en Wodak \& Meyer, p. 67). 

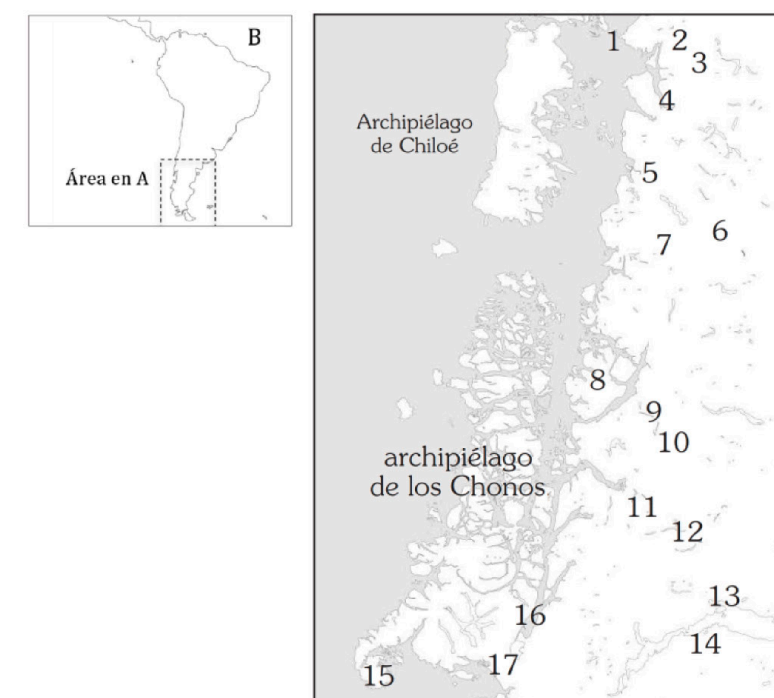

Fig. 1. A y B) Localización general área de estudio. 1 seno del Reloncaví 2 río Manso 3 río Puelo 4 estero Comau 5 río Yelcho, 6 Palena 7 río Palena 8 isla Magdalena 9 río Cisnes 10 río Mañihuales 11 Puerto Aysén 12 Coihayque 13 Lago Buenos Aires 14 Chile Chico 15 cabo Tres Montes 16 laguna San Rafael 17 istmo de Ofqui 18 Tortel 19 río Baker 20 Campos de Hielo Sur

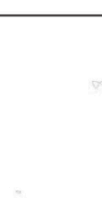


inexplorada, además dan cuenta de cómo dicho conocimiento es procesado y expuesto de manera "oficial" a la opinión pública, compuesta en general por los mismos dirigentes políticos encargados de tomar decisiones sobre Aisén. Por ejemplo el relato de los trabajos al mando de Parker King y Fitz-Roy (18261836) donde se alude al territorio del archipiélago de los Chonos, el límite más al sur de la cristiandad 9 .Y es que a pesar de que estas obras no son producidas directamente por el Estado, contribuyen como antecedentes inmediatos a las futuras expediciones republicanas, iniciándose con ellas una tendencia "cientificista" que marcará la producción documental.

A partir de las expediciones realizadas por la Armada de Chile, el conocimiento geográfico y humano de la zona es ampliado, construyendo una imagen con la que las autoridades de la época discursivamente representan Aisén. Se destacan los viajes de Francisco Hudson (1856) y Enrique Simpson (1870-1873), enmarcándose esta última en una serie de exploraciones hidrográficas encomendadas por el Ministerio de Marina a partir de $1866^{10}$. Lo mismo para la comisión de Ramón Serrano (1885-1887) al rio Palena ${ }^{11}$ y Francisco Vidal Gormaz ${ }^{12}$. Lo significativo de estos informes estriba en que se vuelven casi las únicas fuentes de información producidas in situ durante el periodo, tal y como los informes del primer subdelegado de las Guaitecas, Felipe Westhoff ${ }^{13}$.

El sello "científico" con el que fue explorado Aisén durante el sigloXIX e inicios delXX, tiene surazón de ser en la disputa limítrofe con Argentina, siendo la

9 Fitz-Roy, 1839, Vol. I y II.

10 "Que han dado a conocer porciones considerables de la costa i cursos de algunos ríos hasta aquí no bien estudiados o enteramente desconocidos". Memoria que el Ministro de Estado en el Departamento de Marina presenta al Congreso Nacional de 1870. (1870). Santiago: Imprenta Nacional, p. 27

11 Serrano (1886)

12 Vidal $(1863,1871,1872,1874)$. Además se destaca la Geografía náutica de la República de Chile (1879-1884) interesando aquí la cuarta de ellas: el sondeo del territorio colindante a Chiloé entre el estero Comau y la Isla Desertores (Vidal, 2010, pp. 97-103).

13 Hacia la década de 1870 Westhoff representa la primera autoridad elegida por el Estado chileno con jurisdicción (nominal) sobre los canales más al sur de Chiloé. Felipe Westhoff poseía un conocimiento sobre el territorio aisenino de gran utilidad para los navegantes, ya que era residente permanente, por lo menos desde 1859, de Melinka, primer asentamiento estable de población en la zona. Cabe destacar además que el nombramiento de una subdelegación obra del Dr. Hans Steffen la que explícitamente tiene por objeto la recopilación de información geográfica que sustente la posición chilena en esta controversia (1893-1899) por lo que resulta fundamental su análisis para comprender las motivaciones estatales y su relación con el territorio en estudio. Y dado que son escasos los funcionarios de gobierno que se adentran en la zona durante las primeras décadas del 1900, éstos resultan importantes, pues ellos informan y exponen su parecer sobre las medidas que el Estado toma y/o que debiera de tomar alli ${ }^{14}$. Las actas de sesiones del Congreso Nacional también resultan atingentes al demostrar la postura de las autoridades nacionales sobre Aisén ${ }^{15}$.

Por otra parte, el análisis historiográfico arroja la inexistencia de una producción histórica analítica cuya base sea la resolución de problemas, que es el enfoque de este trabajo, por lo que en su gran mayoría, la bibliografía aisenina responde a un intento de rescate histórico factual, salvo algunas excepciones.

I) La investigación histórica general más completa es "De la Trapananda al Aysén" de Mateo Martinic (2005) autor que ha trabajado profusamente distintos temas ligados a la Patagonia. Trabajo fundamental ya que recoge el carácter de lo que fue la historia y el carácter de su colonización. Este artículo, por tanto, viene a complementar esta obra al introducir, no tan solo una nueva mirada historiográfica

marítima, único atisbo de autoridad en los archipiélagos australes, fue el resultado de una propuesta elevada por el Intendente de Chiloé debido al incidente donde el capitán de la goleta norteamericana "Violeta", hizo flagelar en Guaitecas a tres vecinos de Quellón en marzo de 1865 , quedando este crimen impune. Memoria que el Ministro de Estado en el departamento del Interior presenta al Congreso Nacional de 1866. (1866). Santiago: Imprenta Nacional. 209. Véase también Westhoff, F. (1867), pp. 446-450

14 Pomar, J. (1923). Dentro de este informe se encuentra un mapa puede consultarse por separado en Pomar, J. (1923). Mapa de la zona central de Aisén, Pieza 53, Colección: sección Chilena, Biblioteca nacional, 1923. Otros funcionarios enviados al Aysén son Oportus Mena y Carlos Lemus. Oportus (1928) y Lemus (1927).

15 Los diarios de las sesiones del Congreso Nacional entre 1846 y 1973 se encuentran digitalizadas en su totalidad en el portal de Historia política legislativa del Congreso Nacional. Biblioteca del Congreso. Disponible en http:// historiapolitica.bcn.cl/historia_legislativa\#f $=2, p=1$ 
sino que también al emplear diversas fuentes emanadas por autoridades centrales, las que brindarán valiosos antecedentes para comprender la dinámica Estado-territorio. Leonor Ovalle (2011), por su parte, presenta un panorama con los aspectos más relevantes sobre el contexto histórico, económico y geográfico de la "provincia de Aisén" durante sus veinte primeros años. Las obras de Baldo Araya (1999) y Mario González (1998), representan un intento de rescate cultural sobre diversos aspectos relacionados esta área, por ello abarcan tópicos tan disimiles como la presencia humana en época prehistórica y reflexiones sobre la cultura autóctona, dejando a la posteridad una imagen heterogénea de la vida en aquellas latitudes aunque sin un hilo analítico mayor.

II) En lo que respecta a obras generales con capítulos o referencias sobre Aisén, destaca Izquierdo, quien estudia la colonización de la región, concluyendo que este proceso se inició recién a fines del siglo pasado, en forma escasa y espontánea, y sólo en algunas áreas muy especificas (Izquierdo, 1990, p. 102) enfatizando que los asentamientos espontáneos representaron la forma más efectiva ocupación, cuestión en lo que concuerda René Peri (1989). Sin embargo el objetivo de esteúltimoes entregar una "reseña" histórica del proceso migratorio acaecido en territorio nacional, limitándose a describir los eventos acontecidos de manera disgregada.

III) Respecto de los trabajos cuyo objetivo es estudiar algún aspecto de la vida en aquel territorio destaca Danka Ivanoff ${ }^{16}$, una investigadora aisenina, con una serie de publicaciones sobre hitos específicos como la "Guerra de Chile Chico" (1999) o la

16 La autora se aboca a la presentación de los hechos que gatillaron el enfrentamiento armado, aportando documentos por ella recopilados, de modo de contribuir a su mejor entendimiento. Al alero de este controversial tema han surgido otros trabajos complementarios los que, sin embargo, no difieren en lo sustancial de sus apreciaciones: Carreño (2003, 2011).

17 Ivanoff (2009) e Ivanoff (2007).

18 Parte importante de estas publicaciones responde a los historia de sus poblados ${ }^{17}$. No obstante más que analizar, se dedica a describir aquellos temas que investiga, pues su objetivo es el rescate histórico fundamentalmente.

Por otra parte, la mayoría de los trabajos publicados en la Revista Chilena de Historia y Geografía tratan sobre la posición que ocupa (y ha ocupado) Aisén en la división territorial nacional, preguntándose acerca de si su régimen jurídico está vinculado con Magallanes, Chiloé o Llanquihue, utilizándose de manera transversal como argumento de prueba de una postura y/o ideología determinada ${ }^{18}$. También en el plano jurídico destacan Arturo Montecinos (1946) y Alberto Galilea (1966): el primero, analiza la colonización sobre la base de la legislación existente con el fin de entregar un panorama que contribuya a dar solución a la despoblación y escasa explotación económica y el segundo, estudia la constitución de la propiedad territorial privada en el área. En ambos casos se advierte el patente desconocimiento con que el Estado nacional opera en aquellos parajes.

Con todo, una obra resulta de suma importancia dado que emprende el análisis de algunas aristas de nuestro problema: Adolfo Ibáñez Santa María (1972-1973) expone cómo esta zona se encontraba a fines del siglo XIX despoblada, y donde la acción complementaria entre Estado y particulares no había dado frutos como en el resto del país, lo que lleva al autor a estudiar las causas de la iniciativa estatal de poblamiento versus la realidad, manifestándose un patente desconocimiento de las autoridades por el contexto regional, lo que llevó a incorporar a Aisén pasivamente.

IV) Por último, existen investigaciones que indirectamente entregan antecedentes relevantes sobre Aisén y su relación con el Estado. En esa lógica Mateo Martinic

debates suscitados en torno a temas controversiales que involucraban tanto al Estado, el cual era al mismo tiempo el organismo patrocinador de esta publicación, como a particulares, en los territorios al sur de Puerto Montt. Ejemplo de ello son los artículos ligados al "Caso de los Rabudos", la delimitación fronteriza con Argentina y en menor medida la apertura del istmo de Ofqui. Thayer Ojeda (1918), Gómez (1912) y Grève (1917). 
al estudiar la historia de Magallanes hace alusión a esta innominada zona ya sea por los intereses creados de empresarios puntarenenses vinculados a la explotación ovina como también por encontrarse esta área dentro de la jurisdicción magallánica ${ }^{19}$.

En conclusión, se ha determinado que las publicaciones que estudian la historia aisenina lo hacen de manera descriptiva, su fin más que la posible respuesta a un problema, es el rescate histórico, por lo cual este trabajo resulta un aporte historiográfico al no remitirse tan solo al establecimiento de los hechos que dieron vida a esta región sino que también al incorporar una nueva óptica en su estudio, enfatizando el tratamiento conceptual y metodológico sistemático, incorporando la visión generada desde el centro del país respecto de esas tierras.

\section{PARTE I: LA GENESIS DE UN DISCURSO ESTATAL: EXPLORACIONES EN AISÉN SIGLO XIX}

\section{La posición jurídico-administrativa de}

"Aisén" luego de la Independencia

En lo que respecta a las fronteras nacionales los gobernantes chilenos no se preocuparon por fijar las fronteras certeramente, de hecho en 1810 se acuerdan los primeros límites con Argentina mediante el Utti Possidetis, el que solo mantiene el status quo pre independentista. Es más, el proyecto de constitución provisoria de 1818 solo contemplaba tres provincias: Santiago, Concepción y Coquimbo, sin hacer mención alguna a los límites nacionales. Y aún cuando la Constitución de 1822 describe los confines de Chile, éstos son del todo imprecisos, dividiendo al país en ocho provincias, sumándose a las tres anteriores, Aconcagua,

19 Aysén y Magallanes desde la Colonia fueron consideradas bajo dominio español y luego chileno, pero sin una delimitación exclusiva, adscribiéndosele su pertenencia a Chiloé. Martinic (1977, 2011). Otros trabajos que refieren en parte al Aysén son Martinic (1992, 2011, 2002).

20 Las constituciones consultadas fueron en orden: Constitución provisoria de 1818, Disponible en http://www.camara. $\mathrm{cl} /$ camara/media/docs/constitucion/c_1818.pdf; Constitución de 1822, Disponible en http://www.
Colchagua, Maule, Valdivia y Chiloé. Lo mismo para la constitución de 1823 y para el proyecto de "leyes federales" de 1826. De esta manera, hasta 1828, se circunscribe Chile a los difusos límites del despoblado de Atacama por el norte, el cabo de Hornos por el sur y de cordillera a mar en sentido este-oeste. Finalmente, la constitución de 1833 , solo se remite a refrendar lo ya expuesto en materia limítrofe $e^{20}$.

Todo lo anterior trajo consigo una serie de efectos colaterales durante el siglo XIX (y aún después) pues por ejemplo, el tratado de 1881 entre Chile y Argentina que venía a resolver un conjunto de desacuerdos geográficos respecto de una serie de territorios sur-australes, se volvió el germen de ulteriores disputas, producto "de la ambigua redacción y de la falta de criterios geográficos" (Morales, 1996, 210) con que fue redactado, a lo que se sumaría el desinterés estatal por zanjar definitivamente estos asuntos como se aprecia en las constituciones.

¿Cómo eran percibidas las zonas sur-australes por las autoridades centrales del país en el siglo XIX?

El Estado de Chile no mantuvo en general a lo largo del siglo XIX una política clara y determinada respecto de la zona que va del Reloncaví al sur, asumiéndose que el territorio nacional acababa administrativamente en Chiloé aunque se extendiera jurisdiccionalmente hasta el Cabo de Hornos. Aisén no constituye una zona independiente del sector magallánico, pues las magistraturas de la época ante su desconocimiento, englobaron en un conjunto uniforme, "La Patagonia", a los restantes territorios al norte y al este del estrecho. De hecho en 1861 al crearse la provincia de Llanquihue, ésta limitaba imprecisamente en su extremo sur con el territorio de Magallanes. Lo que dos años más tarde, al crearse el departamento más austral de Llanquihue,

camara.cl/camara/media/docs/constitucion/c_1822. pdf; Constitución de 1823, Disponible en http://www. camara.cl/camara/media/docs/constitucion/c_1823. pdf; Constitución de 1828, Disponible en http://www. camara.cl/camara/media/docs/constitucion/c_1828.pdfy Constitución de 1833, articulo $1^{\circ}$, Disponible en http:// www.leychile.cl/Navegar?idNorma $=137535 \&$ tipoVersi on $=0$ 
Carelmapu, se confirmaría pues el sur de esta última división estaría bajo jurisdicción administrativa de Magallanes (Martinic, 2005, pp. 4-76).

La anterior división estaría dada por la priorización geopolítica (además del desconocimiento geográfico aisenino) del estrecho de Magallanes. De otro modo no se concibe la fundación del fuerte Bulnes en 1843 y la defensa de su complemento, la Tierra del Fuego ${ }^{21}$, descartando como relevantes la Patagonia Occidental y Oriental. Sirva como ejemplo que el Ministro Frías de Relaciones Exteriores de Argentina (1872) diferenciaba y separaba de la Patagonia el estrecho y la Tierra del Fuego, bajo la noción de territorios distintos pero contiguos (Irarrázabal, 1966, p. 121) cuestión que fue aceptada en adelante por Chile y corroborada en 1881 , si se analizan los artículos uno, dos, tres y cinco de dicho tratado.

Dentro del contexto nacional dos elementos permitirian también comprender el porqué de las decisiones nacionales respecto del estrecho y la consideración general, sobre las tierras suraustrales: A) la manera de hacer política de la época y de las ideologías que permean a los grupos dirigentes (liberalismo y el positivismo) y B) la visión de Aisén y de las tierras australes como un territorio problemático y carente de valor en sí mismo, a raíz de la información hasta allí conocida y que hablaba de la presencia de indígenas, por lo menos desde el Biobío al sur, el desconocimiento casi total de las áreas meridionales de Puerto Montt, y lo confuso que resultaba determinar su propiedad.

21 Ilustrativas son las declaraciones del gobernador del Territorio de Magallanes (1853-58), Jorge Scythe (o Schythe), quien dice que no se ha de echar pie atrás en la supervivencia de la colonia, pues la constitución en su primer artículo hace llegar hasta el Cabo de Hornos el territorio chileno, por lo que su abandono haría perder mucha eficacia a esta declaración e implicaría una serie de problemas con las naciones extranjeras ya que éstas "[...] aprecian en su justo valor la importancia que les presta [a las costas del Estrecho] su situación jeográfica, i los recursos que ofrecen para el futuro desarrollo de la navegación y el comercio" (Schythe, 1855, p. 465).

22 El liberalismo es de compleja definición pero evidentemente en lo económico es opuesto al proteccionismo, se minimiza el rol del Estado y se enfatiza la libertad para comerciar. Aunque en el plano político este pasaba por "la temprana adopción del constitucionalismo entre 1810 y 1833, con una preeminencia del régimen republicano, el principio de separación de poderes y las declaraciones de derechos
El siglo XIX verá nacer a un nuevo personaje: el político liberal"2, quien "unía a preocupaciones intelectuales de alto vuelo, fines rápidos e inmediatos" (Villalobos, 2001, p. 313) lo que traducido a consideraciones particulares como el caso de la defensa del Estrecho y la "indolencia" respecto de la Patagonia, sería indicativo de la actitud de los tomadores de decisiones durante aquel siglo. Y es que salvo las notables excepciones de Miguel Amunátegui o Adolfo Ibáñez entre otros, la mayoría de los políticos-intelectuales nacionales manifestaban su deseo de que Chile no defendiera sus derechos sobre la Patagonia (Encina, 1959, p. 104), incluso, entre los banqueros, capitalistas y terratenientes, la idea de una ruptura con la Argentina por la Patagonia era percibida como irracional $^{23}$. Baluarte de esta posición fue José Victorino Lastarria quien en la época que ejercía como enviado diplomático a la Argentina (1865) comienza a interiorizarse en la filosofía positivista de Comte $e^{24}$, lo que será indicativo que los políticos chilenos, se convencerán de que es necesario echar mano del "rigor científico" para conocer el país pues ¿cómo gobernar si no se sabe cuánta población existe, qué recursos se poseen ni qué territorios son propiamente chilenos?

De modo que la "difusión de estas nociones positivistas coincide con una nueva etapa de profundización y ampliación de la actividad científica del país, entendida como acopio cognitivo del cuerpo físico del país, y como conocimiento útil vinculado al desarrollo tecnológico nacional" 25 .

asociadas a los textos constitucionales" (Moyano \& Moyano, 2012, en Fernández, pp. 146-147).

23 Historia General de las Relaciones Exteriores de la República Argentina, Capítulo 36: Las relaciones con Chile. Las percepciones argentinas y chilenas en torno al conflicto limítrofe. Disponible en http://www.argentinarree.com/7/7-001.htm

24 El positivismo es un complejo concepto polisémico debido a sus connotaciones filosóficas, históricas, científicas y epistemológicas. En general se le asocia a una corriente de pensamiento o tendencia científica europea propia del siglo XIX que surge a partir de los postulados de Augusto Comte y Stuart Mills, quienes (sobre todo el primero) exponen la importancia del método científico y de la ciencia, pues ella permitiría alcanzar el progreso material y moral. Además del propio Lastarria, otros intelectuales positivistas y políticos destacados, son Valentín Letelier y los hermanos Jorge, Juan Enrique y Luis Lagarrigue (Saldivia, 2011).

25 Ibídem (p. 188). 
Así el positivismo refuerza la idea de generar un conocimiento in situ, el cual serviría para confirmar los juicios ya expresados sobre algunos territorios. En efecto, el propio Lastarria dirá en su obra La Patagonia, que la solución al problema entre ambas naciones debe pasar por "una sentencia arbitral fijada en el terreno por geómetras y geógrafos expertos, sin intervención de reyes ni de consejeros áulicos ni particularmente de abogados" 26 , la cual dirimirá el que la parte occidental de la Patagonia, la zona frígida pero pastosa y vegetal (al parecer únicas características conocidas por este autor), quedará en manos de Chile.

Ello habría motivado a los hombres de ciencia nacionales a iniciar un proceso de organización de expediciones cuyo destino eran los confines del territorio chileno con objetivos no solo científicos, sino también comerciales, políticos y militares. La necesidad de alcanzar conocimiento de primera mano se hacía acuciante, no tanto para integrarlos a Chile, sino en cuanto su conocimiento les permitiría alcanzar una mayor facilidad de desplazamiento hacia el estrecho o incluso hallar un paso interoceánico anterior a éste.

\section{INACTIVIDAD ESTATAL Y EXPLORACIONES BRITÁNICAS}

Esta primera etapa de exploraciones británicas se corresponde con el periodo en que el Estado de Chile comienza a consolidarse tras las luchas por la independencia, de ahí que no se encuentra en sus planes el realizar acción alguna tendiente a hacer presencia efectiva más allá de Chiloé, asumiéndose que la soberanía estaba en manos nacionales, por lo que la única actividad de reconocimiento en Aisén, se encuentra en lo realizado por hidrógrafos británicos entre 1828 y

26 Citado por Irarrázabal (1966, p. 156).

27 En las cercanías de la Isla campana tuvieron tres días de malísimo tiempo, sin nada de sol, expresando en tono algo desolado que a pesar de no ser invierno el clima parecía de esa estación, lo que se convirtió en algo usual (Fitz-Roy, 1839a, pp. 161-163). Es más, durante un momento de junio de 1829, en la bahía Hewett, se hace el recuento de los cuarenta días de viaje de los cuales solo nueve fueron favorables, veinte parcialmente favorables a la navegación por algunas horas y veintitrés donde la lluvia y el viento eran incesantes (Ibídem, p. 256).
1835, en lo que serian los inicios del conocimiento científico de la zona, y por ello, las primeras fuentes desde las cuales el Estado se nutrirá. De hecho el propio O'Higgins llegará a decir sobre las mismas que "con su aporte científico notable fueron descorriendo el velo del misterio que envolvía a esas regiones y a sus habitantes" (Martinic, 1971, p. 32).

Parker King, emprendió la investigación geográfica de la zona del Estrecho y la Patagonia, la que debe entenderse en la conjunción de aspectos geopolíticos y económicos, pues "fueron dispuestas por el Almirantazgo británico, para poder contar con cartografía confiable en un área de gran importancia estratégica" (Ferrer, 1988, p. 98). Así, tras dos años, el capitán Pringle Stokes en el Beagle, se adentra en el golfo de Peñas o Penas en 1828. Su visión respecto del Cabo Tres Montes, resume sus apreciaciones sobre el resto de las tierras australes: the character of the land is the same with that which we had hitherto passed, bare, rugged, rocky mountains, with peaks, and sharply serrated ridges (Fitz-Roy, 1839a, p. 158). Ello es atizado por las constantes referencias a las dificultades en la navegación (que quedan expuestas en la toponimia de la zona) y aquellas de índole climática ${ }^{27}$, una constante, por cuanto sus efectos en la tripulación son devastadores ${ }^{28}$. Todas estas opiniones, argumentadas con registros en terreno, configuran una imagen que paulatinamente irá haciéndose de uso común, incluyéndose en referencias oficiales y que dejarán por sentado un juicio negativo de Aisén en cuanto espacio físico ${ }^{29}$.

Fitz-Roy, quien había tomado el mando de la misión en 1829, encomienda a William Low el levantamiento del archipiélago de los Chonos,

28 Desde que abandonaron Puerto del Hambre, a mediados de abril de 1828, los enfermos de catarro y pulmonía aumentaron. (Ibidem, pp. 163-164) desembocando en que hacia junio la expedición deba de concluir fundamentalmente por este motivo (Ibídem, pp. 180-181).

29 Around us, and some of them distant no more than two thirds of a cable's length, were rocky islets, lashed by tremendous surf; and, as if to complete the dreariness and utter desolation of the scene, even birds seemed to shun its neighborhood. The weather was that in which (as Thompson emphatically says) 'the soul of man dies in him (Ibídem, p. 179). 
abasteciéndose en Caylin, también llamado El fin de la cristiandad ${ }^{30}$, denominación interesante de analizar pues deja la idea de ser ésta el último rincón civilizado, aspecto que posiblemente influyó en la consideración de las autoridades chilenas al constituirse aquellas tierras en una verdadera frontera imaginaria que comienza a recién develarse con estos aportes científicos ${ }^{31}$.

Ya finalizando su labor, Fitz-Roy decide seguir explorando las costas chilenas al norte de Chiloé, arribando a Valparaíso con el fin de pedir autorización, lo cual resulta llamativo pues cabe la pregunta de si esta solicitud tiene por fin explorar la zona central de Chile la que estaría bajo jurisdicción nacional $y$, teniendo en vista que ya se habian terminado los reconocimientos patagónicos, ¿Por qué no existe una petición similar con anterioridad? $¿ \mathrm{O}$ es que las potencias extranjeras veían esos territorios realmente como res nullius?:

[Fitz-Roy]: I sent Lieutenant Wickham, who spoke Spanish, and had been at Santiago before, to show my instructions to the Authorities, and request their approval of our examination of the shores under their jurisdiction. Nothing could be more satisfactory than the reply (Appendix No. 20), and from that time until the Beagle left Chile she received every attention and assistance which the Chilian officers could afford (Fitz-Roy, 1839b, p. 361).

Como sugiere el análisis del fragmento anterior, existe un contraste entre las pretensiones (teóricas) nacionales de soberanía sobre la zona al sur de Puerto Montt y lo que en la práctica ocurría, donde Chile recién en 1843 hace presencia soberana efectiva en el extremo sur.

Las consideraciones del naturalista Charles Darwin en la expedición de Fitz-Roy, por otro lado, aportan interesantes antecedentes antropológicos y

30 Fitz-Roy (1839b, p. 363).

31 Este concepto indicaría la posición que ocuparian estas tierras en el imaginario de las autoridades políticas, dado que se supondría la existencia de particularidades fuera de lo común, pero que en general responden al escaso conocimiento científico de las mismas. Básicamente sería una línea que separa lo conocido de lo desconocido, lo útil naturales, sin embargo, el juicio negativo del propio Darwin respecto de la Patagonia, considerándola de tierra estéril y de "desolación del sur", caló hondo en los gobernantes chilenos pues hasta bien entrado el siglo XIX, aquella imagen era recordada por eminentes personalidades políticas ${ }^{32}$. Es más, Bacigalupo y Yudilevich proponen que no tan solo en lo referido a la Patagonia (y su concepción negativa) habrían surtido injerencia sus opiniones, toda vez que el interés demostrado por Andrés Bello quien conoció de estas exploraciones e incluso publicó fragmentos en la prensa oficial (El Araucano), sugieren que "los mencionados escritos, sumados a su influencia personal en los medios políticos e intelectuales contemporáneos, hayan servido para impulsar al gobierno de Manuel Bulnes a establecer la primera base militar chilena en el Estrecho de Magallanes" (Bacigalupo \& Yudilevich, 1998, p. 9). En un sentido similar, Facchinetti, Jensen y Zaffrani, (1997) proponen que hacia fines del siglo XIX predominan en diferentes autores, entre los que se encuentran el chileno Vicuña Mackenna y el argentino Irigoyen, las ideas de la "Patagonia maldita" de Darwin y de la "Patagonia encantada", utilizadas con el fin de persuadir o presionar a la opinión pública (pp. 65-66), de modo que tanto estas expediciones británicas como las ulteriores enviadas por cuenta del Estado chileno, se vuelven un recurso argumentativo que (in)válida una posición política sobre la pertenencia de la Patagonia a Chile o los limites con Argentina.

\section{OPERACIONES HIDROGRÁFICAS DE LA ARMADA 1856-1887. "EL PROBLEMA" DE LA PATAGONIA PARA EL ESTADO CHILENO.}

La necesidad de mejorar el conocimiento geográfico de la región austral para los gobiernos nacionales, resultó una demanda acuciante ya que existía en aquella zona un creciente número de embarcaciones que surcaban el mar en busca

para el Estado y aquello carente de provecho (Valhondo, 2010).

32 "La enorme polvareda que las ideas de Darwin levantaron en los medios científicos y teológicos hizo que muchos se abanderizaran en su favor o en su contra. Diferentes personalidades lo defendieron con energía, especialmente sus amigos del viaje del Beagle" (Mansilla, 2004, p. 23). 
de los terrenos para la explotación económica de flora y fauna. Se pretendía además asegurar las rutas que seguían los navíos en sus travesías por el estrecho de Magallanes, "mediante la utilización de los canales del Archipiélago de los Chonos como parte de eventuales trayectos" (Martinic, 2005, p. 71).

Los viajes de la Marina nacional desde mediados del siglo XIX son deudores de la labor de los británicos, lo cual queda reflejado por ejemplo, en el análisis del catálogo de los trabajos hidrográficos, cartas y mapas sobre la geografía nacional publicados hasta 1863 por la Armada, gran parte de los cuales (47 de 55) tiene su correspondiente (aunque con diferencias en distancias) en los trabajos realizados por el Almirantazgo Británico ${ }^{33}$. Sin embargo, marcan un punto significativo en la relación Estado-territorio ya que desde este momento las autoridades centrales pudieron contar con información más completa de la ya conocida.

En 1856 el teniente Francisco Hudson realiza la primera comisión hidrográfica de envergadura a la zona aisenina ${ }^{34}$, tiempo después a lo realizado por los británicos, debido entre otros factores, al periodo de "inactividad" propio de las primeras décadas republicanas y a las limitadas condiciones técnicas de la Armada. En un oficio enviado al General de Marina el 21 de febrero de 1856, explica Hudson que leyendo los apuntes

33 Trabajos hidrográficos de la Marina de Chilena, i catálogo de los planos y cartas hidrográficas i topográficas que sobre esta materia existen en el Ministerio del ramo (1863). Anales de la Universidad de Chile. 23. Julio-diciembre, pp. 611-617.

34 De los escasos datos existentes se colige que este marino chileno es de origen chilote (isla de Quinchao) y nacido en 1826, ingresando a la marina en 1845 con el grado de guardiamarina, siendo promovido rápidamente hasta el cargo de Teniente, llegando en 1850 a servir bajo las órdenes del capitán Muñoz Gamero en el Janequeo.

35 "Leyendo en varias ocasiones la obra del capitán Fitz-Roy, celebre marino inglés, i consultando al mismo tiempo sus planos y cartas de la costa entre el estrecho de Magallanes i la Isla de Chiloé, he encontrado que puede haber un canal que atraviese la península de Tres -Montes i comunique con los otros canales inmediatos" citando como evidencia el capitulo IX Vol. II, pasaje 274 del referido marino inglés. Comunicación del Teniente Hudson, Valparaíso, 21 de Febrero de 1856. En Documentos Parlamentarios. Discursos de apertura en las sesiones del Congreso, i Memorias Ministeriales en los tres últimos años del y cartas dejadas por Fitz-Roy ha encontrado la posible existencia de una vía que, atravesando la Península de Tres Montes, comunique ésta con otros canales ${ }^{35}$, lo que permitiría ir desde Chiloé al Atlántico sin necesidad de escapular por Tres Montes. Así emprende una expedición (enero de 1857) que "buscaba el reconocimiento de estos archipiélagos [Chonos y Guaitecas], y con verdadera ansia deseaba encontrar la comunicación que con el tiempo se evidenciaría en el istmo de Ofqui actual" (Sepúlveda, 1998, p. 5). Sus resultados fueron magros ya que la comunicación entre los canales interiores de los Chonos y el golfo de Penas no se pudo hallar, sin embargo, el conocimiento adquirido a base de los planos levantados, los primeros de la región ${ }^{36}$, y la idea en que se estructura el archipiélago, resultan fundamentales, dando una imagen a las autoridades sobre lo que allí existía. Sin embargo, su repentina muerte (marzo de 1859) privó de cualquier sistematización del conocimiento adquirido y como dirá una carta de Fonck a Domeyko, sus aportes al conocimiento geográfico quedarán solo como una tentativa aislada, pues se sorprende que si el mapa construido por Hudson no se publica se perderá, siendo deseable que el gobierno prosiguiera explorando ya que los trabajos de Moraleda y Fitz-Roy han dejado un gran vacio; $i$ he admirado siempre que el gobierno no emplee su Marina para llenarlo ${ }^{37}$.

Posiblemente la distancia temporal, entre la

primer quinquenio de la administración Montt, 18541856. (1859). Tomo V. Santiago: Imprenta del Ferrocarril, p. 649 .

36 Se levantaron los planos de los canales de Dalcahue o Quinchao, Bahía de Hach y archipiélago de los Chonos y de la Península y archipiélago de Taitao según lo consigna Pedro Lucio Cuadra en los Anales de la Universidad de Chile en 1866 , pues se sabe de la existencia de una publicación de 1859 realizada en base a las observaciones de Hudson, bajo el nombre de "Plano de Península y Archipiélago de Taitao, con informe sumario", en los referidos Anales, sin embargo, no ha sido posible dar con ella hasta el momento, por lo que tampoco es posible saber a ciencia cierta la cantidad de los mismos ni su información concreta (Cuadra, 1866, pp. 266-276).

37 Jeología (sobre la) de las inmediaciones de la colonia alemana de Puerto Montt. Extracto de una carta del Dr. D. Francisco Fonck a D. Ignacio Domeyko, comunicado a la Facultad de Ciencias Físicas i Matemáticas (1859). Anales de la Universidad de Chile. XVI (tercera entrega). Imprenta el Ferrocarril, p. 322. 
expedición de Hudson y la de Simpson se deba a la no consecución de resultados del primero, pero también a que en décadas posteriores a la guerra contra la Confederación Peruano-Boliviana los gobiernos privilegiaron la organización jurídicoadministrativa de la Armada antes que su poder de combate $^{38}$. De este modo Simpson emprende cuatro campañas sucesivas encargadas por el Ministerio de Marina y cuyos objetivos aunque variados, pueden sintetizarse así: reconocimiento de la Patagonia occidental al sur del grado $44^{\circ}$ L.S. en busca ya sea de pasos hacia el oriente o bien vías que permitan la navegación directa atravesando la península de Tres Montes; formar planos de las regiones exploradas; recoger especímenes de "historia natural" (flora y fauna) y, hacer notar terrenos que pudieran interesar a la colonización, aunque esto resultó secundario como adelante se verá.

La expedición de Simpson, se explicaría bajo el contexto controversial respecto de la propiedad del territorio patagónico oriental, además hacia la década de los 70' la Marina comienza a vivir un periodo de consolidación institucional que la llevará a formar la Oficina Hidrográfica, encargada de recopilar y sistematizar la cartografía nacional, volviendo muy necesaria la información para ciertos lugares descuidados en su reconocimiento.

En su primer viaje, se le instruye a que tome contacto en Guaitecas con Felipe Westhoff, subdelegado del archipiélago, lo que confirma que a pesar de los viajes anteriores, el conocimiento oficial sobre Aisén sigue siendo sumamente incompleto y en manos de quienes viven allí. Westhoff ratifica lo que la Marina Británica ya había dado cuenta en parte: la total despoblación y carencia de actividades económicas relevantes, a pesar de la existencia de recursos naturales abundantes, explicando que lo que produce el archipiélago son las simplemente naturales, como es fácil de suponer donde no existe ni población fija, ni algo a que pueda verdaderamente llamarse industria, $i$ aun aquellas están mui distante de ser siquiera superficialmente esplotadas (Westhoff, 1867, pp. 446-447).

A partir de aquella parcial información

38 La Armada de Chile en el siglo XIX. Una institución en formación para un Estado en formación, Memoria Chilena,
(Marina británica, Hudson, Westhoff y sobre todo Simpson) se iniciaría con gran fuerza la construcción histórica de un discurso en que se articula la representación de Aisén como un espacio de difícil acceso, de imperfecta geografía y deshabitado. Muy lejos de la colonización contemporánea de Llanquihue por ejemplo, pues al decir de Domeyko, es natural que el objeto principal de la colonización en Chile no deba ser tanto desde luego poblar el país, como la mejora de sus hábitos i costumbres, el progreso de su industria i laboriosidad (Domeyko, 1850, p. 4), cuestión que visiblemente no sucedía en Aisén.

Simpson también propone que el Estado organice la vida en las zonas donde exista población "blanca", aunque sea esta itinerante (chilotes). En las faenas temporales de tala del ciprés por ejemplo, se emplean más de tres mil trabajadores, los que actúan sin sistema de vigilancia alguna, destruyendo a menudo el resto del bosque para aprovechar el ciprés, y llegando hasta quemar islas enteras (Simpson, 1874, p. 19). Sin embargo, la acción estatal es nula ¿condicionada por los antecedentes hasta ahí recopilados? Es probable, sumado al hecho que resolver estas dificultades en tan "solitarias" tierras no tendría ningún efecto directo ni beneficio para el resto del país, representándose esta área como un problema que se ha de resolver, aunque no hay prisa en ello.

En su segundo viaje, entre 1870 y 1871 , se le solicita a Simpson que prosiga sus trabajos de exploración del rio Aisén hacia el oriente, a fin de reconocer cursos de agua que permitan la comunicación interoceánica. Como se aprecia, nuevamente el objetivo emanado desde el gobierno central es la búsqueda, por su importancia estratégica y geopolítica, de un paso hacia el Atlántico, influido principalmente por las reclamaciones argentinas sobre la Patagonia. Aprovecha el capitán de insistir en su reproche hacia la no regulación de la tala de bosques debido a lo lamentable que es ver el desperdicio con que se explota esa riqueza que constituye el principal porvenir de esta provincia (Ibídem, p. 45-46), lo que también ocurre con las focas, elefantes y leopardos marinos que cuarenta

Biblioteca Nacional de Chile. Disponible en http://www. memoriachilena.cl/602/w3-article-3498.html 
años atrás eran abundantes, pero que en aquél momento eran muy escasos ${ }^{39}$.

Durante su tercera exploración reconoció el valle del rio Aisén hacia sus orígenes en la cordillera. Comprueba la inexistencia de un paso marítimo directo con el golfo de Penas como se había conjeturado, además describe, con motivo del encuentro de una conservera de choritos, las posibilidades económicas que ofrecen dichas comarcas. Un aliciente para que el Estado cambiase su percepción sobre estos territorios a una situación de menor abandono, pues es tal el desamparo de ayuda fiscal, dice el subdelegado en la zona, que no ha podido realizar trabajo útil de información para el gobierno ${ }^{40}$.

Propone la idea de establecer dos colonias en la Patagonia Oriental, la que a su juicio es más accesible por el Pacifico, sin costo para el Estado, sin embargo, no pasan de ser meros proyectos que no constituyen el eje central de sus expediciones. Es muy probable que esta idea tuviese, como plantea Martinic, la intención de llegar a oídos del Presidente o a su ministro de Relaciones Exteriores (Federico Errázuriz y Adolfo Ibáñez respectivamente), pues el contexto estaba atravesado por las reclamaciones argentinas sobre la Patagonia Oriental, lo cual explicaría la necesidad geopolítica estatal por adquirir conocimiento científico de un territorio que solo muy marginalmente, salvo las comisiones británicas, era conocido en el centro del país.

Finalmente, entre octubre de 1872 y mayo del año siguiente, se realiza un levantamiento de los canales australes entre $44^{\circ}$ y $45^{\circ}$ de L.S, explorando (nuevamente) la laguna San Rafael. Los resultados de este último viaje confirman muchos de los aspectos que ya había esbozado en sus informes: la variedad extrema de climas, la despoblación y que la mejor accesibilidad a la parte fértil de la Patagonia entre los ríos Negro y Santa Cruz, se encuentra a través del Océano Pacífico.

Tras los viajes de Simpson, no se llevan a efecto otras exploraciones entre los ríos Yelcho

39 El 17 de agosto de 1892 recién se crea una ordenanza que regula la caza de focas, nutrias, lobos marinos y chungungos, la que finalmente termina suspendiendo esta actividad hasta 1897, aunque ello representa de todos modos una acción tardía y "reactiva" de parte del Estado, toda vez que para fines de siglo, la población de esto se mamíferos estaba desapareciendo (Briones, 1905, pp. 609-611).

40 "No habiéndose efectuado todavía el Supremo Decreto, y Baker. La Guerra del Pacífico es sindicada como la gran causante de esta ausencia de reconocimientos. Además se iba menoscabando en Chile el interés por la Patagonia considerada ya como un páramo, sin valor alguno y sin condiciones de civilización posible (Orrego, 1902 , p. 15), y aunque esta última afirmación se centraba sobre todo en la parte oriental, su contraparte no era ajena a este juicio, como se ha hecho notar anteriormente, en una imagen que la propia institución castrense contribuyó a generar. A pesar de ello, Vidal Gormaz concreta el proyecto de poner por escrito una sintesis actualizada de la hidrografía de las costas chilenas desde las expediciones británicas hasta las recientes de la Marina, incluidos sus propios viajes a la región circundante a Chiloé: la Geografía náutica de la República de Chile, entre 1879 y 1884 . Se destaca el que las islas no tienen pobladores fijos y sólo la frecuentan algunos pescadores en ciertas épocas del año, por lo que no ofrecen recurso alguno (Vidal, 2010, p. 103), lo cual refuerza la percepción respecto a la "despoblación" al sur de Chiloé, aspecto transversal a los reconocimientos practicados en toda la Patagonia occidental, y por ende una constante que contribuye a levantar una imagen del "incivilizado" territorio aisenino. La información que afluye hacia el Estado configura entonces una representación donde las dificultades son un punto central, pues si no hay población estable ¿Qué aliciente ofrecen estas tierras al Estado?

Luego del receso obligado de la Guerra del Pacífico, se reinician las exploraciones con Ramón Serrano al río Palena. Sus objetivos generales son dos: A) el acopio de datos hidrográficos mediante el levantamiento de un plano sobre el Palena y sus afluentes, estableciendo las coordenadas geográficas para determinar la línea del divortia aquarum y posición de ésta respecto de las cumbres más altas de los andes

por el cual se dota a esta subdelegación marítima con una chalupa tripulada, el infrascrito se ha visto con frecuencia embarazado en el desempeño de sus funciones, sin contar con no poder practicar ningún trabajo de utilidad pública por falta de recursos". Subdelegación Marítima de Melinka. Memoria de Guerra i Marina presentada al Gobierno Nacional en sus sesiones ordinarias de 1877 (1877). Santiago: Imprenta Nacional, p. 259 
(Serrano, 1886, p. 78), hecho no menor debido a la acida polémica por el límite sur-austral y B) recoger datos que permitiese calificar si existían o no las posibilidades para establecer una colonia agrícola, toda vez que las noticias que se tienen sobre las condiciones del mencionado valle son muy vagas y aún contradictorias (Ibídem, p. 77).

Esta expedición tiene un afán geopolítico, aunque esta vez la idea de asentar población es más acuciante, ya que Argentina había iniciado un desplazamiento hacia el sur del río Negro, disponiendo "una movilización armada tendiente a liquidar los restos de la resistencia aborigen" (Barros, 1984, p. 49) a fines de 1878, lo que no ocultaba sus pretensiones de tomar posesión de la Patagonia ${ }^{41}$. Bajo esta lógica, el viaje de Serrano sería una respuesta estatal ante el "problema" de la Patagonia. De hecho Martinic (2005), considera que el fracaso de la colonia de Palena (fundada en 1889) se debería no tan solo a causas como la desidia del gobierno central sino que a un motivo soterrado: la reclamación del canciller argentino Zeballos, y que estaría en consonancia con la política oficial del periodo en cuanto consolidar la soberanía en el Estrecho y en lo demás, evitar cualquier problema con Argentina (p. 117).

Implícitamente es posible estimar que en su informe, Serrano, apunta a que una intervención estatal allí, podría redundar en reales beneficios (sobre todo económicos) pues de otro modo, preveía que condicionado por la imagen que se estaba construyendo de esta zona, no actuaría decididamente. Así el entusiasmo con que se miró Palena pronto desapareció cuando las rentas no afluyeron con fuerza hacia el centro del país (como si sucedía con el norte minero por ejemplo), en lo cual ha de verse también la insistencia con que Rosselot enfatiza que aún, a pesar del estado deplorable de la colonia en 1894, aún puede reactivarse ya que aquella tierra tiene vida i promete un vasto

41 Incluso durante 1878 y a raíz del continuo avance argentino al sur de Rio Negro, casi estalla un conflicto bélico, al hacer apresar las autoridades chilenas a la barca norteamericana "Devonshire" quien cargaba guano en la desembocadura del río Santa Cruz, territorio chileno, con autorización de Argentina. Antes de romper relaciones diplomáticas, se llegó a un acuerdo mediante el tratado Fierro-Sarratea de i provechoso desarrollo. A esto contribuye el convencimiento que se tiene de que la calidad del terreno, aparte de las abundantes maderas de construcción, las hace aptas para el cultivo de la cebada, avena, trigo, papas, betarraga, i con especialidad la crianza del ganado (Rosselot, 1894, p. 175).

\section{HANS STEFFEN, PUNTO CULMINE DE LA CONSTRUCCIÓN DISCURSIVA DE LA PATAGONIA OCCIDENTAL}

En 1881 Chile celebró un tratado con Argentina, donde se establece que los limites comunes se encontrarian en la Cordillera de los Andes, corriendo la línea fronteriza por las cumbres más elevadas de dichas Cordilleras que dividan las aguas i pasará por entre las vertientes que se desprenden a un lado i otro ${ }^{42}$. No obstante, en poco tiempo se pudo comprobar que había sido adoptado más de un punto geofísico referencial para la demarcación fronteriza, lo que con el añadido de la complejidad y extensión del territorio en disputa, acrecentó las reclamaciones entre ambos países.

En vista del desconocimiento de aquellas zonas que hacia impracticable una solución definitiva desde el monte Tronador (41 ${ }^{\circ}$ L.S) y hasta el fiordo Última Esperanza (52 $2^{\circ}$ L.S), es que se nombran peritos, los que al no llegar a acuerdo, derivan la disputa al arbitraje de la Corona Británica, de manera que las exploraciones de ambas partes, servirían como medios de prueba. Los problemas derivados de la "cuestión de límites", acentúan la imagen del área austral como espacio que entrega tan solo inconvenientes al Estado. En tal situación se inserta la labor del geógrafo alemán Hans Steffen, quien es comisionado a terreno por el perito chileno Barros Arana.

Con Steffen finaliza un largo proceso que desemboca en la construcción de un discurso sobre

1878, aun cuando éste no fue aprobado por las Cámaras del Congreso Argentino (no así por Chile), volviéndose entonces un antecedente del posterior acuerdo transaccional de 1881 (Lagos, 1980, pp. 43 ss).

42 Tratado de 1881, Art. $1^{\circ}$, citado en Rodríguez (1985, p. 52). 
Aisén basado en aspectos geográficos. Al sistematizar el conocimiento que el Estado poseía de manera fragmentada a través de los viajes de exploración británicos y luego nacionales, este geógrafo contribuye a delimitar la Patagonia Occidental, siendo el pionero en intentar explicar geográficamente la fisonomía de una imagen construida a lo largo de los años. No obstante, sus descripciones retratan lo ya esbozado por la Armada, pues no veía del terreno que pisaba sino lo que el terreno tenía interés para un geógrafo; lo demás, por lo menos así lo demuestra en su libro [Patagonia Occidental] no existía para él (Rojas, 1947, p. 28).

El primer viaje oficial (1893-1894) al río Palena y alrededores, tenía por propósito la búsqueda de su nacimiento, información fundamental para determinar los límites naturales reales entre los países en disputa. Tanto aquí, como en las anteriores exploraciones chilenas, la expresión geográfica de los resultados se vuelve esencial para el Estado: era más importante el conocimiento natural (clima, geografía, flora y fauna) de la zona, que la existencia de habitantes, lo cual puede deberse a que el territorio se asumía indudablemente como "vacío".

La resolución del "problema" patagónico es lo esencial para Steffen, quien pensaba que los argumentos geográficos (a pesar de ser un problema político también) le darían la razón a Chile, sin embargo, esta posición, centrada en criterios técnicos, se enfrentó a las presiones políticas que más bien buscaban arribar a acuerdos de modo de acelerar la solución de la disputa (Sanhueza, 2012, p. 43), en lo que resulta sintomático respecto de Aisén: las demandas del gobierno central contrastan con las pretensiones de quienes en terreno pueden apreciar a cabalidad dicha zona.

En 1895 Steffen junto a su equipo, se dirigió hasta el río Puelo remontándolo en su totalidad. También exploró el río Manso, comprobando que su parte superior posee ventajas para establecer colonias agrícolas. Propuesta similar a la de Serrano Montaner, sin embargo, éste se preocupa marginalmente por la colonización.

La comisión al rio Aisén, fue organizada el 14 de octubre de 1896. Se reconoció su hoya, descubriendo y explorando su brazo norte (Mañihuales), a fin de resolver prontamente la divisoria de aguas entre dicho río y los arroyos que abastecen al Senguer. Ello denota que la preocupación central del Estado está en conocer la geografía de Aisén a pesar de que paradójicamente el laudo se resuelva, principalmente, por criterios demográficos para los jueces británicos.

En esta extensa zona, escasamente conocida y de difícil acceso, Steffen se ve obligado a realizar una transferencia de saberes geográficos al ámbito político vinculando tanto los requerimientos de quienes lo habian contratado, como las exigencias de la ciencia geográfica de su tiempo (Ibídem, p. 42), convirtiendo sus informes per se, en la fuente de referencia estatal a la hora de "imaginar" esta área. Sin embargo, ya habían pasado más de cincuenta años en que sucesivas exploraciones habían aportado a la construcción de un discurso sobre lo que era Aisén, viniendo este geógrafo, tan solo a corroborar algunos aspectos ya conocidos (en teoría). Ejemplo de ello lo constituye su viaje de exploración al río homónimo entre diciembre de 1896 y mayo del año siguiente, donde expresa la idea de que esta área es un "desierto", sin valor, pues de otro modo no podría explicarse que hasta la fecha no existe ninguna comunicación regular entre las regiones habitadas de la República y el río Aisén (Steffen, 1897, p. 73).

En el siguiente viaje (1897-98) explora la región del río Cisnes estudiándola orográficamente, siendo éste su gran mérito, pues "hasta entonces sólo era conocido en su desembocadura, [descubierta por Simpson en 1873] aportando informaciones que más tarde sustentaron la línea fronteriza en el litigio con Argentina" (Sanhueza, 2012 , p. XX) y finalmente, a contar de diciembre de 1898, se recorren los fiordos sur-australes y la hoya del río Baker (Bahía Exploradores a Seno Elefantes), debiendo incluso cruzar la laguna San Rafael por el istmo de Ofqui. Su objetivo "era comprobar el curso de los grandes ríos y los 'desaguaderos' de los lagos, hoy conocidos como el Carrera-Buenos Aires, Cochrane-Pueyrredón y O'Higgins-San Martín" (Sanhueza, 2010, p. XXI). Esta travesía se llevó a efecto en un territorio hasta entonces completamente desconocido e inhabitado. De hecho, los restos encontrados de la empresa de Buenaventura Sánchez, dedicada a la explotación de hielo flotante, no eran sino establecimientos temporales. 


\section{PARTE II: EL ESTADO DE CHILE Y Aisén: LA CONSTRUCCIÓN Y EXPANSIÓN DE UN DISCURSO}

El Estado chileno aparece solo "tímidamente" y actuando mediante una imagen a priori de esta zona, entre la resolución del Laudo arbitral con Argentina (1902) y la creación del Territorio de Aisén (1927) y más tarde provincia (1929), consolidando un discurso construido en sus bases a lo largo del siglo anterior. Desde las políticas públicas, son las grandes concesiones la manera en que los gobiernos de la época, en base a su conocimiento parcial de la zona, junto al centralismo y adhesión al librecambismo económico, pretenden ocupar y "desarrollar" la región al sur del seno del Reloncaví. Sin embargo, éstas resultan poco efectivas, generándose desde el punto de vista de la ocupación inicial un "desarrollo bipolar, que se vio reflejado en un orientación divergente del territorio" (Villagrán, Núñez \& Hidalgo, 1997, p. 13) al desconocer la ocupación espontanea que simultáneamente acaecía, privilegiando a empresarios en desmedro de colonos individuales ${ }^{43}$, en una actitud siempre a la zaga de los problemas suscitados, entre la ignorancia y la reactividad.

\section{El Estado y la delegación de responsabilidades en manos de privados}

Una vez resuelta la cuestión limítrofe, el Estado se vio en la posesión de un patrimonio territorial que no bajaba de 10 millones de hectáreas entre el fiordo Comau y el monte Fitz Roy, disponiendo de una enorme extensión de tierras que eran consideradas "vacías" de habitantes, sin una legislación especial acorde y que no contaba con una posición administrativa determinada. Con el escaso conocimiento adquirido merced de las exploraciones del siglo XIX, el Estado pretendió ocupar y explotar Aisén, valiéndose para ello de

43 Mientras los pobladores espontáneos (pequeña propiedad) se asentaban en el sector oriental del territorio aisenino, con salida natural hacia Argentina, los concesionarios de terrenos (gran propiedad) se vinculaban más estrechamente hacia el Pacifico, ya sea por el Puerto Aysén o por algún improvisado puerto que pudiera establecerse en las cuencas hidrográficas. particulares (personas naturales o sociedades).

Al analizar las grandes concesiones fundiarias efectuadas por el Estado, se refuerza un discurso caracterizado por la indolencia y la actuación a posteriori, lo cual no es ajeno a la manera en que aquella época los distintos gobiernos manejaban los temas concernientes a la ocupación de las áreas sur australes, tal como lo deja ver el informe enviado al Ministro de Relaciones Exteriores (1901), por el Inspector General de Tierras y Colonización, Agustín Baeza, quien cataloga de fracaso aquella colonización de parte de Llanquihue y sobre todo la de Chiloé, tanto por lo onerosa, la deficiente preparación de los colonos y la mala situación de las hijuelas como por la falta de caminos y medios de comunicación ${ }^{44}$. Mientras más al sur más costoso resulta al Estado la instalación de colonos, por lo que en ello podría encontrarse una de las primeras razones de las concesiones territoriales al sur del paralelo $41^{\circ}$.

Se afirma por tanto que la Colonización de los territorios correspondientes a la actual provincia de Aisén, empieza tardíamente, como consecuencia de los éxitos económicos conseguidos en Magallanes (Ovalle, 2011, p. 89). $Y$ es que no siendo suficientes las tierras aprovechables allí, se inició una expansión económica hacia Argentina (Santa Cruz), Tierra del Fuego y lo que es más significativo, hacia zonas mal conocidas o enteramente ignotas de la Patagonia Occidental $^{45}$. Por ello a inicios del siglo XX muchos especuladores de tierras vieron la posibilidad de lucro en la vastedad de los terrenos baldios que se situaban en general al sur del fiordo de Reloncaví y hasta la península Muñoz Gamero" (Martinic, 1977, p. 6), en los fondos de los valles aiseninos, siendo Punta Arenas y Valparaíso los núcleos que sustentaban estas empresas.

En Magallanes es el arrendamiento en lotes de mediana extensión la forma de tenencia del suelo. Se pregunta Gooycolea (1942) ¿por qué, teniendo tantas similitudes Magallanes y Aisén, en esta última

44 Informe del Inspector de Tierras y Colonización al Ministro de Relaciones Exteriores. (1901). Archivo Nacional de la Administración. Ministerio de Relaciones Exteriores, Culto y Colonización. N¹555. Vol. 1029. Santiago 20 de Noviembre de 1901.

45 Martinic (2002, pp. 64-94). Capítulo Los años dorados (1906-1920). 
las autoridades nacionales conceden gratuitamente grandes extensiones de terrenos a pesar de solo conocer alrededor de un $20 \%$ de su superficie? Respondiéndose que los gobiernos que crearon esta legislación [actuaron con el deseo] de obtener inmediatamente utilidades que incrementen las entradas del presupuesto nacional aún a costa del futuro de esas regiones (p. 52).

Si se comparan la ocupación y explotación de Magallanes y Aisén, resulta que esta última se asemeja a lo acaecido en la isla grande de Tierra del Fuego tanto porque usufructuaron de ella empresarios ajenos a la zona ${ }^{46}$, como porque la manera de obrar del presidente Santa María resultaba una novedad, dado que si hasta ese entonces en las cercanías al Estrecho se habían entregado en arriendo campos en fracciones de superficie variable, en ningún caso mayor de 300.000 hectáreas, en la Tierra del Fuego se optó por la forma del latifundio, [...] que sería la única que se utilizaría en este territorio insular (Martinic, 2012, pp. 7-8).

Aisén tanto como Tierra del Fuego eran áreas escasamente conocidas, que para "integrarlas" al resto del país era necesario ponerlas en explotación inmediata, en lo posible sin generar costos para el Estado, por lo que entregarlas a privados era la solución más inmediata, delegando a empresas la responsabilidad de ocupar el territorio pero sin regulación alguna salvo, para el caso de Aisén, la ley de 4 de agosto de 1874 en su artículo undécimo y los artículos $509^{\circ}$ y $602^{\circ}$ del Código Civil, concesionando la totalidad del territorio continental y algunos sectores insulares a diecisiete concesionarios, quienes solicitaron tanto permisos para llevar a cabo una ocupación económica, como para colonizarlos, aunque ambas actividades no fueron excluyentes entre sí.

Esta laxitud estatal para concesionar, trajo consigo una serie de problemas derivados de la onerosa puesta en marcha de las mismas, dado

46 César, Hernán y Augusto Wehranhn en 1883, que contaban con una casa comercial en Valparaíso, se unieron a su mandatario y factor Rodolfo Stuberauch residente de Punta Arenas para dar origen a una sociedad de explotación ganadera en la Isla grande Tierra del Fuego, a la que en 1888 se les une Ernesto Hobbs y Luis Baillon (hacendado de las Islas Malvinas) formando así la Sociedad Wehranhn, que en general, la explotación económica resultaba desmesurada para una sola persona o incluso sociedades, ya que solo la cabida de algunas de ellas iba desde islas enteras (como la Melchor o Magdalena) hasta hoyas hidrográficas completas. A ello se suma el casi total desconocimiento del Estado y de los solicitantes sobre la fisonomía del área, y las dificultades producto de la disputas entre empresarios y colonos individuales re-emigrados desde Argentina por la tenencia de la tierra, atizado por la lejanía de las autoridades gubernamentales.

Dado que las regiones australes permanecían aún muy desconocidas, el apresuramiento estatal al entregar los decretos (principalmente entre el 19 de junio y 22 de octubre de 1903) demuestra que su interés, más que por una importancia intrínseca, resulta de una concepción que veía como un "problema" el poseer comarcas sin presencia humana que antes estuvieron en disputa, y es que a la región del Aisén se le asignó muy poca importancia geopolítica, tanto a fines del siglo pasado como a comienzos del actual (Peri, 1989, p. 112), por lo que se delegó rápidamente su cuidado a manos de privados. De hecho, las medidas tomadas, sin demasiada información y con intenciones de satisfacer problemas inmediatos, tuvieron consecuencias impensadas, toda vez que contemporáneamente se iniciaba un proceso colonizador "espontáneo" en lo que se creía, eran grandes extensiones de tierras "orejanas" (desocupadas). El Estado, desconocedor de este proceso, trató de imponer el mejor derecho de sus dictados, con el resultado de producir violentos enfrentamientos entre ambas partes (Ibáñez, 19721973, p. 314).

\section{Entre el poblamiento espontáneo $y$ las concesiones fundiarias}

A diferencia de las grandes empresas ganaderas, lo que motiva a estos migrantes es la tenencia de la tierra para poder vivir en paz, teniendo un mejor pasar ${ }^{47}$. El Estado se enfrentó a este

\section{Hobbs y Cía. (Martinic, 1982, pp. 50 y ss.)}

47 Al tipo de colonización de esta zona del país se le suele considerar "espontánea", entendiendo a esta como "aquella realizada esporádicamente, sin una planificación gubernamental e incluso sin el conocimiento de parte del gobierno" (Izquierdo, 1990, p. 102) 
proceso desde una actitud de indiferencia atizada por su desconocimiento de la zona y sus dinámicas, hacía la reactividad, esto es, reaccionar ante los problemas luego de producidos éstos, incluso con posterioridad al establecimiento de la subdelegación de río Simpson (1915), primer atisbo continental de autoridad, pues como se verá, en la práctica ello no modificó sustancialmente la relación Estado-territorio.

El proceso de colonización aisenino fue efectuado por sujetos de origen y condiciones diversas aunque con una característica común a la gran mayoría: un paso previo por Argentina. No obstante, no fueron la única corriente migratoria, pues como Galindo demuestra, entre 1902 y 1928 existían tres "tradiciones" diferenciables en las zonas del Valle Simpson, Coihaique, Lago Buenos Aires y Baker: los empleados de la Sociedad Industrial de Aisén (contratados en las provincias de Llanquihue y Chiloé), sus administradores (de origen europeo, como ingleses o escoceses) y los pobladores particulares, chilenos de la zona centro sur del país con un paso por Argentina (Galindo, 2008, pp. 5758), además de algunos llegados desde Magallanes.

Como se ha indicado, la contraposición existente entre dos formas, opuestas, de ocupación del territorio dio origen a una serie de dificultades respecto de las cuales el Estado no hizo mayor eco. $\mathrm{Su}$ actitud, dichos y las disposiciones tomadas sobre los eventos que con fuerza se comenzaron a vivir especialmente en la zona central de la Patagonia Occidental, refuerzan la hipótesis sobre la existencia de un discurso que representa a dichas tierras como de poca o nula importancia, de hecho, los encargados del Departamento de Tierras y Colonización, quienes velaban por el cumplimiento de las disposiciones estatales en lo referido a la colonización, no sabían a cabalidad lo que estaba ocurriendo en la zona de Aisén y solamente se dejaban llevar por los alegatos de estos grandes accionistas pertenecientes a la elite nacional (Álamos, 2010).

\section{La Subdelegación del Río Simpson y el viaje de José Pomar}

Los pobladores del valle Simpson en varias ocasiones elevaron solicitud a fin de radicarse en la zona, sin embargo, sus iniciativas no tuvieron acogida en el gobierno central pues éste iba por un rumbo diferente al de los esperanzados aspirantes a colonizadores, pues tenía decidido dar lugar a lo propuesto por la S.I.A., en cuanto a la permuta de sus campos no ocupados de Mañihuales y Emperador Guillermo, por los de la zona norte del Valle Simpson (Martinic, 2005, p. 171) cuestión ratificada por decreto $\mathrm{N}^{\circ} 1.882$ del 23 de noviembre de 1914.

El poblamiento espontáneo del valle Simpson es desconocido por las autoridades, concesionando a Luis Aguirre una parte de esta zona (origen de la S.I.A), e incluso por decreto $\mathrm{N}^{\circ}$ 794 se les cedía a Antonio Asenjo y Alejandro Bate los valles de los ríos Palos, Blanco y Simpson, los cuales por transferencia pasan a ser parte de la Sociedad Explotadora del Valle Simpson, devenida en Sociedad de los Tres Valles. A pesar de que ésta nunca pudo tomar para sí estos territorios, no deja de ser decidora la actitud del Estado, la que sin más información que aquella proporcionada por los propios solicitantes, termina por entregar todas las tierras disponibles sin considerar y probablemente sin siquiera saber, de su ocupación previa.

Con la permuta referida se le exoneraba de introducir familias sajonas pero debiendo traer 200 familias nacionales además de dar facilidades y pagar los gastos al delegado que el gobierno nombrara, clausula respecto de la cual surge inmediatamente una pregunta ¿este funcionario del que se habla será quien deba hacerse cargo de la Subdelegación de Río Simpson que se creará al año siguiente? Y en tal caso ¿al hacer esto el gobierno no se arriesga a que este funcionario termine bajo dependencia de la concesionaria?

Bajo el contexto de demandas de parte de los pobladores e intento de la empresa por ocupar los campos permutados, es que se debe entender la creación de la $7^{\text {a }}$ Subdelegación del Río Simpson (departamento de Llanquihue), por medio del decreto $\mathrm{N}^{\circ} 3.024$ de 7 de junio de $1915^{48}$, primera expresión del ordenamiento institucional público en el territorio de Aisén, aunque de rango inferior

Administración. El texto del decreto se encuentra citado en Martinic (2005, p. 176).
48 Se ha podido constatar que este decreto se encuentra extraviado, como asimismo los antecedentes que lo deberían de acompañar, del Archivo Nacional de la 
(Ibídem, p. 176) dependiente de Puerto Montt en lo administrativo, y cuya extensión iba desde el río Rayas hasta el paralelo $47^{\circ} \mathrm{L}$. S., de mar a cordillera. Y si bien en la practica el subdelegado no percibió remuneración, tal como consta en un informe enviado por éste al intendente de Llanquihue (1922) y que cita Pomar, no deja de ser decidora tal propuesta levantada por el Estado en la clausula de permuta, en orden a no prever las consecuencias que podría traer esta disposición, tal y como ocurrió con los carabineros mantenidos por la misma compañía, que en la práctica actuaban defendiendo sus intereses. A pesar que Martinic considere que la creación de la subdelegación resulta trascedente, lo cierto es que como dirá Pomar, citando al propio subdelegado: las autoridades en los cantones salitreros y los subdelegados y jueces en Magallanes son remunerados y tienen atribuciones especiales que les permite obrar con firmeza por contar con la fuerza armada. No hay [tales] garantías en la $7^{a}$ subdelegación (Pomar, 1923, p. 107). Dada la gran extensión del territorio, las comunicaciones dificultosas y la poca monta de la subdelegación, ello conllevó a que esta delimitación administrativa fuera muy parecida a nada (Ibáñez, 1972-1973, p. 313).

$\mathrm{Al}$ iniciar la S.I.A. el cobro a los pobladores por concepto de talaje en los terrenos que le pertenecían, se temió un inminente desalojo al negarse éstos a pagar, sin embargo, aquello no llegó a concretarse, aunque generó gran alarma entre los ocupantes. Y si bien el problema de la presencia de pobladores en el lote 3 (norte del valle Simpson) persiste, lo cierto es que parte importante de los problemas, habían acabado sin mediación estatal, por lo que el envío del ingeniero José Pomar a la zona en abril de 1920, debe verse como un intento tardío de parte del gobierno central por "informarse" de los sucesos allí acaecidos, como bien lo expone el propio ingeniero en carta al delegado del directorio de la S.I.A. (17 de julio de $1920)^{49}$.

49 "[...] cuando todavía estaban frescos mis mejores recuerdos de mi estada en Aysén, al llegar a Santiago me impuse con estrañeza (sic) de la presentación que Ud. ha hecho al Ministerio de Colonización, en la que tomando como personal un asunto puramente administrativo y dando un carácter de agresividad, que jamás tuvo, a una comisión más que todo de información, Ud. Señor Terry aprovecha
Tras el fin de su viaje, el 27 de junio de 1920, y haciendo un atento análisis de su informe, es posible colegir que a pesar de todas las recomendaciones entregadas por Pomar, ninguna de ellas llegaría a materializarse a pesar del amplio panorama socio-cultural presentado por este funcionario. En efecto, la ley especial de colonización para Aisén solo llegará una década después (ley N4.855 de 1930), contemporánea a la constitución de un territorio autónomo que él proponía se instituyese. Tampoco fue considerada su recomendación de colonizar hasta las cercanías del Puerto Aisén internando colonos de Puerto Montt o Chiloé (Pomar, 1923, pp. 19-24). Incluso en lo que respecta a la rectificación de los límites de la sociedad a los que poseía en 1904, el ingeniero da cuenta del error cometido por las autoridades que a pesar de tener en vista todos los antecedentes, fijan su límite occidental extendiéndolo hasta el río Aisén, lo que genera un serio problema, dado que deja fuera todo el puerto homónimo donde la S.I.A. tiene asiento y salida al Pacifico, lo que es confirmado en $1921^{50}$.

Por lo visto, le es más lucrativo a las autoridades conservar trabajando esta empresa, de ahí su preferencia por ésta en desmedro de los pobladores, quienes en una presentación realizada en Santiago solicitan la obtención de 21 y luego 479 hectáreas, siendo ambas rechazadas por el Ministerio de Tierras. En otras palabras, a pesar de la información entregada in situ por Pomar y las peticiones de los pobladores a fin de radicarse, el Estado mantiene una sola postura, debido al discurso con el que representa esta zona y del cual se ha venido probando su construcción y cristalización.

\section{"La Guerra de Chile Chico"}

Este evento está relacionado con la aparición de Carlos Von Flack en la zona aledaña al Baker y lago Buenos Aires, como asimismo con

mi ausencia para tratar de denigrar mi persona, faltando a la verdad del modo más lamentable". Correspondencia entre Enrique Terry, Gerente SIA y José Pomar, Funcionario de Gobierno. Abril-julio 1920 (Sociedad de Historia y Geografía de Aysén, 2010, pp. 9-10).

50 Pomar (1923, Nota 7). 
el desconocimiento con que opera el Estado en materia de concesiones. Y es que el citado Von Flack se hizo con algunos animales de la extinta Compañía Explotadora del Baker, formando empresa con Braun y otros, disolviendo estos últimos la sociedad para formar una compañía propia. Sin embargo, Von Flack se quedó en la zona y gracias a sus contactos (era pariente político del Ministro de Colonización del momento) pudo hacerse con la subasta de terrenos al sur del Lago Buenos Aires, el 1 de marzo de 1917, por sobre Julio Vicuña Subercaseaux quien había solicitado tal remate en un principio (Carreño, 2003, pp. 127 y ss).

Dado que el inserto en el Diario Oficial que anunciaba el evento, según el diputado Nolasco Cárdenas, era sumamente pequeño y con un arribo tardío en lugares a más de 300 leguas de la capital, hace dudar de si verdaderamente no fue una omisión deliberada para perjudicar a los ocupantes que a la fecha residían alli51. El propio Cárdenas, cita un informe del gobernador del Territorio de Magallanes, para corroborar lo anterior, donde se expone que los remates en áreas de su jurisdicción se hacen sin considerar los intereses de los habitantes de la zona. Por lo visto, el Estado actúa excluyendo cualquier otra solicitud que no se realice en la capital, lo que habla a las claras tanto de intereses creados como también de la ignorancia sobre los habitantes, sus padecimientos y necesidades, sin pasar por alto el histórico centralismo de la administración pública.

Tras la referida subasta, Carlos, su hermano Rodolfo y el teniente de policía Miquel junto a seis carabineros arriban a la colonia en el lago Buenos Aires, en marzo de 1918, con el fin de, supuestamente, pagar las mejoras introducidas y desalojar. Tras un trato amable, cambian su actitud al enterarse de una entrevista previa que tuvieron éstos en diciembre de 1917 con el ingeniero enviado por la Inspección General de Colonización, Salvador Rivadeneira, que tenía por objeto tasar las mejoras introducidas, pues en dicha entrevista los pobladores explicaron que se resistirian a salir pues eso sería su ruina, además que se les ofrecían

51 "Esto posiblemente no se ha hecho deliberadamente, puesto que podría haber sido una omisión; pero eso no me inhabilita para manifestar que esta omisión iba en perjuicio directo de los ocupantes a quienes el Gobierno precios muy bajos por sus enseres y animales, recordando de paso que tenían el legitimo derecho a estar allí según un decreto del año 1914.

En tales circunstancias y ante la inminencia del desalojo, los pobladores a instancias de José A. Silva, se prepararon para la defensa. Por ello envían al diputado por Valdivia y la Unión, Nolasco Cárdenas, la información de lo que estaba ocurriendo, el cual expresa en sesión del Congreso el 3 de abril de 1918, que ya habían pasado 6 a 7 meses en que se venía advirtiendo de ello, sin que ninguna autoridad tomara medida alguna. Esta actitud del Estado, se condice con la existencia de un discurso (en general negativo) sobre Aisén:

Se creyó [dice Nolasco Cárdenas] que tal vez nosotros exagerábamos al manifestar la situación que ahi se había creado y se nos declaró en forma rotunda que habiendo el Estado contraído un compromiso, por el contrato de remate, el gobierno no se consideraba en situación de tomar ninguna medida en contra de las personas que, en subasta pública, habian obtenido el arrendamiento de esos terrenos. Se dijo que tal vez la situación no era tan grave como nosotros la pintábamos $y$ que se tomarian todas las medidas encaminadas a impedir acontecimientos desagradables, hechos luctuosos ${ }^{52}$.

Así, mientras en Chile Chico el teniente Miquel se retiraba hacia Argentina a pedir refuerzos, recién el Ejecutivo reacciona por medio del Ministerio de Colonización al comisionar un agrimensor el 3 de junio de 1918, Carlos Lemus, para que acuda a la región del Lago Buenos Aires (Lemus, 1927, p. 331-367), junto a un nuevo destacamento de carabineros a raíz del telegrama recibido por el Ministerio del Interior en donde se le informaba, de parte de Miquel y Von Flack, que habían evacuado debido a una numerosa partida de "bandoleros" que les impedía tasar las mejoras y desalojar (Niemeyer, 1981-1982, p. 11).

En un punto transicional entre la indiferencia

tenía motivos para informar sobre esta cuestión". Cámara de Diputados, 50ª , Sesión en 25 de julio de 1918. p. 1232.

52 Sesión $47^{\mathrm{a}}$ ordinaria, en 24 de julio de 1918. p. 1189. 
y la reactividad, tras la tardía y sesgada información recibida, es que comienza a situarse al Estado, pues como dirá el Ministro del Interior, el Gobierno no puede resolver por lo que dice la prensa; tiene que oír informes oficiales de sus funcionarios ${ }^{53}$. Informe que solo será presentado al Ministerio de Colonización el 21 de Octubre del mismo año, tras el regreso de Lemus a la capital el 2 del mismo mes.

Reunidos a fines de junio en la zona sur del Lago, Miquel, Von Flack, Lemus y toda la tropa, se inicia lo que se suponía era la tasación de las mejoras de los pobladores. Sin embargo, tras una golpiza a un ocupante y la negativa de Lemus de realizar su labor bajo esas condiciones, carabineros y pobladores terminan enfrentándose a balazos, finalizando la disputa con la muerte de tres uniformados, malhiriendo a uno y apresando a otros ocho. En el intertanto las noticias en torno a los sucesos del lago Buenos Aires, se divulgaban con caracteres alarmantes tanto en Chile como en Argentina (Mayorga, 1982, p. 298), estimuladas por las comunicaciones enviadas por Silva Ormeño y Von Flack, quien había huido a Argentina. Mientras que los colonos que quedaron en el lago Buenos Aires, esperaron durante tres días la presencia del subdelegado o del juez que residía en Balmaceda. Sin embargo, todo fue inútil, porque las autoridades no se hicieron presentes (Carreño, 2003, p. 138) Como se aprecia, las disputas en el Parlamento, y algunas acciones aisladas del Estado, todas tendientes hasta el final del conflicto, a hacer cumplir sus dictámenes y favorecer al concesionario, también tuvieron su contraparte en dicha zona.

Contemporáneamente, el telegrama del ingeniero Lemus [27 de julio de 1918] fue la primera información directa y oficial que recibieron las autoridades chilenas de un funcionario civil de gobierno que había estado presente en los sucesos (Ibidem, p. 142). Recién en ese momento, el gobierno reacciona y advierte la real magnitud de lo sucedido, telegrafiando a su embajador en Buenos Aires para que ayudara a regresar a los carabineros y a Von Flack se le caduca

53 Sesión $50^{\mathrm{a}}$ ordinaria en 25 de julio de 1918. p. 1234.

54 Cuyos límites eran por el norte el cordón de cerros que divide las aguas entre los ríos Jainemeni y Chacabuco hasta el rio Neff, al Oriente el límite con Argentina, al Sur el cordón de cerros que divide aguas entre el rio Baker y Bravo y al Oeste el rio Baker (Oportus, 1928, p. 6). su concesión, reintegrándosele el dinero dejado como fianza.

A consecuencia de estos hechos, Danka Ivanoff ha postulado que existe una mayor injerencia del Estado en los asuntos de Aisén, dado que existe una mayor fiscalización sobre las concesiones otorgadas, se reduce la cabida de las mismas y se les obliga a pagar los sueldos de los policías que resguardaban el orden en la zona (Ivanoff, 1999, p. 102 y ss). Sin embargo, si bien la Guerra de Chile Chico representa un suceso importante para la historia regional, ella no cambia radicalmente la actitud del Estado, pues el gobierno central actuará enviado un funcionario sin otras autoridades que lo respalden y con carácter de "informante", dado su nulo poder de resolución. Por otra parte, los carabineros en la práctica se volvieron empleados de las concesionarias que les pagaban sus sueldos.

\section{El viaje de Carlos Oportus Mena y la concesión del Baker}

La primitiva concesión otorgada a comienzos del siglo XX y que incluía la zona del Baker a Juan Tornero, quien asociado con capitalistas puntarenenses había dado origen a la Compañía Explotadora del Baker, había quebrado rápidamente quedando los terrenos a disposición de los migrantes que comenzaban a ocuparlos. Sin embargo, a poco andar esta zona ${ }^{54}$ fue puesta en remate por el gobierno central siendo adjudicada por Julio Vicuña Subercaseaux en 1914, el que al contrario de lo expuesto por Ivanoff no trasfiere sus derechos inmediatamente a la Sociedad Posadas Hobbs y cía. (Ivanoff, 2009, p. 91), sino hasta el año siguiente e incluso 1916, dado que no aparece mencionado tal traspaso en la comunicación donde se le cita como adjudicatario del remate producido dos años antes y del cual es necesario hacer desalojo, ya que el Estado está dejando de percibir $\$ 31.500$ pesos al año por concepto de arrendamiento ${ }^{55}$.

Se llama la atención sobre este último hecho

55 Comunicación enviada por el ministerio de Relaciones Exteriores al Ministro del Interior solicitando dos carabineros que notifiquen desalojo y visto bueno del comandante del cuerpo de Carabineros (1916). Archivo Nacional de la Administración. Ministerio del Interior. Vol. 4.616, 9 y 10 de marzo respectivamente. 
pues parece un motivo implícito y transversal en las acciones emprendidas por el Estado respecto de las concesionarias, explicando porque mantiene los remates de tierras a pesar de los conflictos que generan. Bajo esa perspectiva el Estado se despreocupó del drama en que dejó sumido a miles de compatriotas que habian poblado esa tierra y agravó los conflictos al dar en arriendo las zonas de Aisén sin estar al tanto de lo que ocurría en ellas ${ }^{56}$, por lo que la continua amenaza del desalojo de los colonos por parte de la compañía no debe verse simplemente como obra de Lucas Bridges, administrador in situ de ésta desde 1921, pues este proceso como se ve, se había iniciado con anterioridad y con la venia de los gobiernos centrales.

En el intertanto el representante de los pobladores, Adolfo Valdebenito, comenzaba una campaña en los medios de comunicaciones (diario Llanquihue de Puerto Montt) contra la sociedad Posadas Hobbs por lo que él considera es un hostilización de la misma respecto de su ocupación. Así en 1923 llegará a decir que:

Mi campaña contra la concesión Baker ha causado el asombro de las autoridades, porque en realidad ignoraban todos los detalles que he venido develando, desde el momento que se ve un ataque injusto contra sesenta familias chilenas todas, y con un patriotismo digno de ser apoyado y protegido ${ }^{57}$.

Desprendiéndose de aquellas declaraciones que en esa remota región las autoridades nacionales desconocen lo que acontece, pues a pesar de los sucesos del lago Buenos Aires (1918) y de la visita de Pomar al Valle Simpson (1920) las cosas no han cambiado como historiográficamente parece suponerse, sino que más bien son eventos aislados

56 Historia de Ocupación. Fundación Baker. Disponible en http://www.fundacionriobaker.cl/?page=rio_baker_historia

57 Millar (1994), Citado en Ivanoff (2009, p. 89).

58 Funcionario de la sección Colonización, participó en 1920 de la confección de un mapa sobre las concesiones territoriales entre el paralelo $42^{\circ}$ y $52^{\circ}$. José Pomar relata que Oportus casi pierde la vida tras realizar un trabajo a cuenta de un frigorífico en la parte sureste del lago Buenos Aires. Parece ser que "vio de cerca la muerte en 1920, [...] allí, los pobladores aún estaban que no cambian la relación Estado-territorio. De hecho, son las continuas cartas y la campaña que emprende Valdebenito contra la Soc. Hobbs, el motivo por el que los gobernantes prestan atención a los sucesos del Baker, enviando una comisión a terreno.

Un ingeniero del Departamento de Tierras, Carlos Oportus Mena ${ }^{58}$ al que se le unen representantes de las autoridades de Magallanes, tienen por misión levantar un informe de las tierras que se pondrían en arrendamiento tras el fin del contrato de la Sociedad Estancias Posadas, Hobbs y Cía., el cual caducaba en septiembre de 1929. Secundariamente, y solo a instancias del gobernador de Magallanes, se le solicitaba que determinara la cantidad de población existente, viviendas, animales y nacionalidad entre otros aspectos (Oportus, 1928, pp. 5-6).

De acuerdo a lo anterior, en 1928 el gobierno central solo va a "informarse" de los sucesos del Baker, teniendo por fin primariamente dilucidar el destino del arrendamiento de la sociedad y no el de establecer algún tipo de medida permanente respecto del modus vivendi entre pobladores y la empresa. Una de las preocupaciones del gobierno central era de índole económica, esperándose que la producción de lana saliera por el Pacífico, hacia puerto chileno, lo que recién se logró tras la asunción de Bridges como gerente de la estancia en el Baker. Así, en vista de todos los antecedentes, y a pesar de los continuos reclamos de los pobladores, el informe elevado a las autoridades centrales, favorecía a la Sociedad arrendataria, pues se demostró que todos los pobladores, con los cuales aquella tenía problemas, eran ocupantes del terreno cuyos arriendos anuales eran cancelados por la compañía (Ivanoff, 2009, p. 111)

En 1929 el Estado llegó a un acuerdo con Posadas, Hobbs y Cía., prorrogándole por

nerviosos con los sucesos acaecidos en 1918 y que costaron la vida a 3 carabineros y 1 civil. Desconfiaban de todo agente del Estado y eso se tradujo en un asalto armado directo a Oportus y su comitiva, del que logró salir ileso no sin dificultades". Sociedad de Historia y Geografía de Aysén (2012). Carlos Oportus Mena antes de 1928. Recuperado de http://sohigeo.wordpress. com/2012/04/04/carlos-oportus-mena-antes$\mathrm{de}-1928 /$ 
veinte años el arrendamiento, aunque reduciendo a 230.000 sus hectáreas, de las cuales la mayor parte se encontraban ocupadas. Así, en vez de buscar otra alternativa éste mantiene el status quo anterior, no resolviendo el conflicto entre pobladores y concesionaria, lo que lleva a concluir que el análisis de estos eventos demuestra que este proceso colonizador constituye un fenómeno social atípico sin mayores puntos de comparación en la historia nacional, fundamentalmente por la manera en que las autoridades centrales actuaron respecto de esta área marginal del territorio nacional.

\section{CONCLUSIONES}

Para optimizar el conocimiento geográfico al sur de Chiloé, el Estado nacional por medio de la Marina, patrocinó una serie de expediciones tendientes a satisfacer las necesidades de una mejor navegación las que, siendo deudoras de los anteriores reconocimientos británicos, arrojaron como resultado el que durante el siglo XIX y comienzos del XX, se fuera construyendo una representación en forma de discurso sobre Aisén, aunque de manera "incompleta" en su fisonomía, por medio de noticias vagas $y$ aún contradictorias, conocida solo por los que se aventuran a vivir en sus inmediaciones (por ejemplo Westhoff o Lagreze), y que intenta ser retratada lo más optimistamente posible por la Marina pero ello contrasta con la cruda realidad que demuestran sus informes, cuestión que termina por reforzar Steffen con sus expediciones al servicio de la causa chilena en el laudo fronterizo con Argentina.

Al avanzar el siglo XX, el interés del Estado radicó en la obtención de rápidos ingresos, sin que para ello resultase un gasto pues las inversiones y demás peligros, recaían en los particulares, concordante con la política económica liberal de fines del siglo XIX y afín a una imagen que comienza a extenderse y consolidarse bajo la forma de un discurso, lo cual al mismo tiempo permite explicar el origen y desarrollo de eventos tales como la "Guerra de Chile Chico" o la visita de informantes de gobierno a la zona.

Es por lo anterior que la propuesta enunciada en un comienzo, ha sido corroborada en cuanto se ha verificado que desde la segunda mitad del siglo XIX y hasta 1929 aproximadamente, se aprecia la construcción histórica de un discurso sobre el territorio patagónico por parte del Estado de Chile, el que va asentando algunas características (negativas muchas de ellas), que condicionan el propio actuar del Estado, siendo éste conformado por dos etapas sucesivas A) la primera de ellas originada en las diversas expediciones hidrográficas y la información que estas entregan a los diversos organismos gubernamentales desde inicios de la era republicana y hasta fines del siglo XIX, y B) un segundo momento, marcado por la construcción y expansión de una representación discursiva sobre Aisén implícita en las acciones y dictámenes estatales, pudiéndose hablar de que el significado otorgado a Aisén y las características asignadas a él, se vuelven una constante histórica.

Se puede apreciar una actitud de parte del Estado, hacia 1929, que se sostiene aquí es de larga data, y que explica la existencia de una representación discursiva sobre el territorio, la cual se ha ido edificando a partir de los primeros acercamientos a éste. Entre los elementos constituyentes de este discurso se encuentran: el patente desconocimiento en torno a las dificultades y el modus vivendi de los habitantes de Aisén, el marcado centralismo con que se establecen las políticas públicas sobre esta zona (cuando las hay), la manera de concebir la marcha del país de parte de los políticos nacionales entre las que se cuenta su tendencia hacia el régimen liberal (sobre todo en su vinculación económica) y junto a ello la delegación de responsabilidades que efectúan a privados de materias cruciales para el desarrollo de aquella área (colonización, integración económica, construcción de obras de adelanto material, entre otras), la fluctuante acción fiscal en dichas tierras que suele variar entre la indolencia y la reactividad, lo que repercute de manera general, en que el Estado termine actuando a posteriori de ocurridos los eventos y finalmente, la caracterización del área que media entre el Reloncaví y Magallanes, como una zona de extremismo natural, es decir, condiciones climáticas sumamente adversas, abrupta geografía y patente despoblación. De acuerdo a ello, una proyección de esta investigación se encuentra en el estudio de las repercusiones generadas a posteriori de la construcción y asentamiento de esta representación discursiva, y la manera en que las características (negativas) que éste consolida, se vuelven un lugar común que alcanzaría hasta nuestros días. 


\section{FUENTES DE CONSULTA}

Inéditas

Comunicación enviada por el ministerio de Relaciones Exteriores al Ministro del Interior solicitando dos carabineros que notifiquen desalojo y visto bueno del comandante del cuerpo de Carabineros. (1916). Archivo Nacional de la Administración. Ministerio del Interior. Vol. 4.616, 9 y 10 de marzo.

Concesión de tierras a José Cámpelo (1902). Archivo Nacional de la Administración. Min.RR.EE. Vol. 1.092, Decreto N ${ }^{\circ}$ 1209, 8 de octubre de 1902.

Concesión de tierras a Luis Aguirre (1903). Archivo Nacional de la Administración. Min.RR.EE. Vol. 1.092, Decreto N ${ }^{\circ}$ 659, 19 de mayo de 1903.

Informe del Inspector de Tierras y Colonización al Ministro de Relaciones Exteriores. (1901). Archivo Nacional de la Administración, Ministerio de Relaciones Exteriores, Culto y Colonización. $N^{\circ}$ 1555. Vol. 1029. Santiago 20 de Noviembre de 1901.

Lagreze, G. (1901). Propuesta para establecer línea de navegación, Archivo Nacional de la Administración. Ministerio de Relaciones Exteriores, Culto y Colonización. Vol. 1.041 .

Impresas

Briones, R. (1905). Glosario de Colonización y exposición de las leyes, decretos i demás antecedentes relativos al despacho de colonización hasta el 10 de julio de 1904 seguido de un apéndice hasta el 10 de abril de 1905. Santiago: Universitaria

Cámara de Diputados. 50ª . Sesión en 25 de julio de 1918.

Comunicación del Teniente Hudson, Valparaíso, 21 de Febrero de 1856 En Documentos Parlamentarios. Discursos de apertura en las sesiones del Congreso, i Memorias Ministeriales en los tres últimos años del primer quinquenio de la administración Montt, 1854-1856. (1859).Tomo V. Santiago: Imprenta del Ferrocarril.

Constitución provisoria de 1818. Disponible en http://www. camara.cl/camara/media/docs/constitucion/c_1818.pdf

Constitución de 1822. Disponible en http://www.camara.cl/ camara/media/docs/constitucion/c_1822.pdf

Constitución de 1823. Disponible en http://www.camara.cl/ camara/media/docs/constitucion/c_1823.pdf

Constitución de 1828. Disponible en http://www.camara.cl/ camara/media/docs/constitucion/c_1828.pdf

Constitución de 1833. Disponible en http://www.leychile.cl/Nave
gar?idNorma=137535\&tipoVersion $=0$

Correspondencia entre Enrique Terry, Gerente SIA y José Pomar, Funcionario de Gobierno, Abril-julio 1920, En Sociedad de Historia y Geografía de Aisén (2010), Fuentes para la Historia de Aisén, 0, Abril, Coyhaique.

Cuadra, P. (1866). Bosquejo geográfico de Chile. Anales de la Universidad de Chile, 28, 266-276.

Viaje de exploración de la Corbeta Chacabuco, N¹6, 15 de diciembre de 1870. En Memoria que el Ministro de Estado en el Departamento de Marina presenta al Congreso Nacional de 1871. (1871). Santiago de Chile: Imprenta Nacional.

Fitz-Roy, R. (1839a). Narratives of the surveying voyages of His Majesty's ship Adventure and Beagle between the years 1826 and 1836, describing their examination of southern shore of South America and the Beagle's circumnavigation of the Globe. I, London: Henry Colburn, Great Malborough Street.

Fitz-Roy, R. (1839b). Narratives of the surveying voyages of His Majesty's ship Adventure and Beagle between the years 1826 and 1836, describing their examination of southern shore of South America and the Beagle's circumnavigation of the Globe. II, London: Henry Colburn, Great Malborough Street.

Fonck, F. (1859). Geología de las inmediaciones de la colonia alemana de Puerto Montt. Extracto de una carta del Dr. D. Francisco a D. Ignacio Domeyko, comunicado a la Facultad de Ciencias Físicas i Matemáticas. Anales de la Universidad de Chile, XVI, 318-322.

Lemus, C. (1927). Diario de viaje al Lago Buenos Aires. Revista Chilena de Historia y Geografía, LIII(57), 331-367.

Memoria de Guerra y Marina presentada al Gobierno Nacional en sus sesiones ordinarias de 1877 (1877). Subdelegación Marítima de Melinka, Santiago: Imprenta Nacional.

Memoria que el Ministro de Estado en el Departamento de Marina presenta al Congreso Nacional de 1870 (1870). Santiago: Imprenta Nacional.

Memoria que el Ministro de Estado en el departamento del Interior presenta al Congreso Nacional de 1866 (1866). Santiago. Imprenta Nacional.

Oportus, C. (1928). Informe sobre el problema de colonización del río Baker. República de Chile, Ministerio de Fomento, Departamento de Tierras y Colonización. Folleto $N^{\circ} 3$, Santiago.

Orrego, L. (1902). Los problemas internacionales de Chile. La cuestión de Argentina. El tratado de 1881 y las negociaciones posteriores. Santiago: Imprenta, encuadernación y litografía Esmeralda. 
Pomar, J. (1923). Tierras de colonización. La concesión del Aisén y el valle Simpson. Santiago: Imprenta Cervantes. Rosselot, E. (1894). Memoria del Inspector de la Colonia de Palena. En Memoria del Ministerio de Relaciones Exteriores, Culto y Colonización presentada al Congreso Nacional en 1894 (1894). Santiago: Imprenta Nacional.

Schythe, J. (1855). El territorio de Magallanes i su colonización. Anales de la Universidad de Chile, 1, 435-465

Serrano, R. (1886). Reconocimiento del río Buta-Palena i del canal Fallos por el vapor de la República "Toro" bajo la dirección del capitán graduado de fragata. Anuario Hidrográfico de la Marina de Chile. Santiago: Imprenta Nacional.

Sesión $47^{\mathrm{a}}$ ordinaria en 24 de julio de 1918.

Sesión 50a ordinaria en 25 de julio de 1918.

Simpson, E. (1874). Exploraciones hechas por la corbeta Chacabuco al mando del capitán de fragata Enrique $M$. Simpson en los Archipiélagos de Guaitecas, Chonos y Taitao. Santiago: Imprenta Nacional.

Steffen, H. (1897). Relación de un viaje de exploración al río Aisén (Diciembre 1896-Mayo 1897). En Steffen, H. (2010). Viaje de exploración y estudio en la Patagonia Occidental 1892-1902, II, Santiago: Biblioteca Fundamentos de la Construcción de Chile. Cámara Chilena de la Construcción, 57-139.

Trabajos hidrográficos de la Marina de Chilena, catálogo de los planos, cartas hidrográficas y topográficas que sobre esta materia existen en el Ministerio del ramo. (1863). Anales de la Universidad de Chile, 23. Julio-diciembre, 609617.

Vidal. F. (1863). Jeografía de Chile. Descubrimiento hecho por el teniente $2^{\circ}$ de nuestra marina de guerra, don Francisco Vidal Gormáz, de los grandes boquetes que dan paso a la pampas arjentinas, a la altura del Archipiélago de Chiloé. Comunicación del mismo en 21 de febrero de 1863, Anales de la Universidad de Chile, XXII. Enero-junio, 670-671.

Vidal, F. (1871). Hidrografía. Esploración de la costa de Llanquihue i archipiélago de Chiloé practicada por orden del supremo Gobierno por el capitán graduado de corbeta don Francisco Vidal Gormaz. Anales de la Universidad de Chile, XXXIX, Julio, 5-80

Vidal, F. (1872).Hidrografía. Esploración de la costa de Llanquihue, practicada por orden del Supremo Gobierno por el capitán de corbeta don Francisco Vidal Gormaz, Anales de la Universidad de Chile, LXI, enero-diciembre, 217355.

Vidal, F. (1874). Reconocimiento del río Maullín por la comisión exploradora de Chiloé i Llanquihue, bajo la dirección del capitán graduado de fragata don Francisco Vidal
Gormaz. Anales de la Universidad de Chile, 45, EneroDiciembre, 567-662.

Vidal, F. (2010). Geografía Náutica de Chile. Santiago: Biblioteca Fundamentos de la Construcción de Chile. Cámara Chilena de la Construcción. Pontificia Universidad Católica de Chile. Biblioteca Nacional.

Westhoff, F. (1867) Memoria del subdelegado marítimo del Archipiélago de los Chonos o Guaitecas. Anales de la Universidad de Chile, 29(7), 445-450.

\section{BIBLIOGRAFÍA}

Araya, B. (1999). El Gran Reportaje de Aisén. Coihaique: Gobierno regional de Aisén del General Carlos Ibáñez del Campo, División Cultural del Ministerio de Educación.

Barros, J. (1984). Palena. Un río, un arbitraje. Santiago: Santillana del Pacífico.

Bacigalupo, J., \& Yudilevich, D. (1998). Andrés Bello y la visita de Charles Darwin a Chile. Ciencia al Día, 1 (1). Abril, 1-11.

Carreño, L. (2003). Los sucesos de Chile Chico, 1917-1918. Un episodio del poblamiento de Aisén. Revista de Historia Social y de las mentalidades, 7, Primavera, 121-147.

Carreño, L. (2011). El ingeniero Carlos Lemus testigo de los sucesos de Chile Chico. En Congreso de Historia Social y Política de la Patagonia Argentino-Chilena. Las fuentes en la construcción de una historia patagónica. Trevelin: Secretaria de Cultura del Chubut, junio, 39-46.

Carrillo, L. (2006). La (lógica) construcción de la realidad. Ámbitos, $15,12-156$

Encina, F. (1959). La cuestión de límites entre Chile y la Argentina desde la Independencia hasta el tratado de 1881. Santiago de Chile: Nascimento.

Facchinetti, G., Jensen, S., \& Zaffrani, T. (1997). Patagonia. Historia, discurso e imaginario social. Temuco: Ediciones Universidad de la Frontera.

Ferrer, H. (1988). Las expediciones hidrográficas y su importancia para las comunicaciones marítimas. En Instituto de investigaciones del patrimonio territorial de Chile. Chiloé y su influjo en la XI región: II jornadas territoriales. Santiago de Chile: El Instituto.

Galilea, A. (1966) La constitución de la propiedad territorial en la provincia de Aisén y el departamento de Palena. Santiago: Memoria de prueba para optar al grado de Licenciado en la Facultad de Ciencias jurídicas, políticas y sociales de la Universidad de Chile.

Galindo, L. (2008). "Chilotes argentinizados", "chilenos agauchados". La compulsiva "chilenización" del Aisén, y sus consecuencias en la percepción de la identidad de sus habitantes. En Sociedad de Historia y Geografía de 
Aisén. Actas III Seminario Un encuentro con Nuestra Historia, Coyhaique: Gobierno regional de Aisén, Lom, 57-62.

Gómez, A. (1912). Dificultades en la delimitación Austral de Chile, Revista Chilena de Historia y Geografía III(7), 231-243

González, M. (1998). Aisén en la Patagonia. Coihaique: Gobierno regional de Aisén del General Carlos Ibáñez del Campo. División Cultural del Ministerio de Educación.

Gréve, E. (1917). Informe sobre la delimitación provincial y departamental en Llanquihue y Chiloé, Revista Chilena de Historia y Geografía, XX(24), 429-468

Goycoolea, M. (1942). Colonización de Magallanes y Aisén. Memoria de prueba para optar al título de licenciado en la facultad de ciencias jurídicas y sociales de la Universidad de Chile, Santiago: Imprenta El Imparcial.

Historia General de las Relaciones Exteriores de la República Argentina, Capítulo 36: Las relaciones con Chile. Las percepciones argentinas y chilenas en torno al conflicto limítrofe. Disponible en http://www.argentina-rree. com/7/7-001.htm.

"Historia política legislativa del Congreso Nacional". Biblioteca del Congreso. http://historiapolitica.bcn.cl/historia legislativa $\# \mathrm{f}=2, \mathrm{p}=1$

Ibáñez, A. (1972-1973) La incorporación de Aisén a la vida nacional. 1902-1936. Historia, 11, 259-378.

Irarrázabal. J. (1966). La Patagonia. Errores geográficos y diplomáticos. Santiago de Chile: Editorial Andrés Bello.

Ivanoff, D. (1999). La Guerra de Chile Chico o los Sucesos del Lago Buenos Aires, Tercera edición, S. I

Ivanoff, D. (2007). Lago General Carrera. Temporales de sueños. Santiago: Consejo Nacional del libro y la lectura, Lom.

Ivanoff, D. (2009). En los confines de Aisén. Historia de la comuna de O'Higgins. Santiago: Consejo nacional del libro y la lectura, Lom.

Izquierdo, G. (1990). Historia de Chile. Tomo III. Santiago de Chile: Editorial Andrés Bello.

Jäger, S. (2003) Discurso y conocimiento: aspectos teóricos y metodológicos de la crítica del discurso y del análisis de dispositivos. En R. Wodak \& M. Meyer(Eds.),. Métodos de análisis crítico del discurso. Barcelona: Gedisa,

Lagos, G. (1980). Historia de la Frontera de Chile. Los tratados de límites con Argentina. Santiago: Editorial Andrés Bello.

Martinic, M. (1971). Presencia de Chile en la Patagonia Austral. Santiago: Editorial Andrés Bello.

Martinic, M. (1977). Ocupación y colonización de la región septentrional del antiguo territorio de Magallanes, entre los paralelos $47^{\circ}$ y $49^{\circ}$ Sur. Anales del Instituto de la Patagonia, 8, 5-57.
Martinic, M. (1982). La Tierra de los Fuegos. Punta Arenas: Impresores Artegraf Ltda.

Martinic, M. (1992) Historia de la región magallánica. Punta Arenas: Universidad de Magallanes.

Martinic, M. (2001). Menéndez y Braun: prohombres patagónicos. Punta Arenas: Ediciones de la Universidad de Magallanes, La Prensa Austral.

Martinic, M. (2002). Breve Historia de Magallanes. Punta Arenas: Ediciones de la Universidad de Magallanes.

Martinic, M. (2005). De la Trapananda al Aisén: una mirada sobre el acontecer de la Región de Aisén desde la prehistoria hasta nuestros días. Serie Biblioteca del Bicentenario. XXXVIII. Santiago de Chile: Pehuén editores.

Martinic, M. (2011). Magallanes en el ordenamiento territorial de Chile republicano. Su expresión cartográfica (18531884). Magallania, 39(2). 37-45.

Martinic, M. (2012) La Ocupación de Tierra del Fuego. Disponible en http://www.tierradelfuegochile.com/ wp-content/uploads/2012/12/la-ocupacion-de-tierradel-fuego.pdf

Millar, S. (1994). La conquista del Aisén. Puerto Montt: Cayenel Ediciones.

Montecinos, A. (1946). Colonización en Aisén, Memoria de prueba para optar al grado de Licenciado en la Facultad de Ciencias Jurídicas y Sociales de la Universidad de Chile. Santiago: Imprenta López Hermanos.

Morales, G. (1996). Conflictos geográficos en las tierras patagónicas chilenas. ERIA. Revista Cuatrimestral de Geografía,41, 206-212.

Moyano, C., \& Moyano, F. (2012). El liberalismo en Chile en el siglo XIX. La formación del concepto, su trayectoria y sus dimensiones. En Fernández, J. (Coord.), La Aurora de la libertad. Los primeros liberalismos en el mundo iberoamericano (pp. 145-180). Ambos Mundos, Madrid: Marcial Pons ediciones de Historia S.A.

Niemeyer, H. (1981-1982). Un episodio del poblamiento de la Patagonia Chilena: la Guerra de Chile Chico. Revista Trapananda, 4, abril, 10-13.

Ovalle, L. (2011). Ocupación y desarrollo de la Provincia de Aisén. Coyhaique: Aisén Gobierno Regional.

Pardo, M. (1992). Derecho y lingüística. Como se juzga con palabras. Buenos Aires: Ediciones Nueva Visión.

Peri, R. (1989). Reseña de la colonización en Chile. Santiago: Editorial Andrés Bello.

Saldivia, Z. (2011). El positivismo y las ciencias en el periodo finisecular del Chile decimonónico. Araucaria. Revista Iberoamericana de Filosofía, política y humanidades, 13(25), 182-193

Sanhueza, C. (2010).Viajes de exploración y estudio en la 
Patagonia Occidental. En Steffen, H. (2010). Viaje de exploración y estudio en la Patagonia Occidental 1892-1902, II., Santiago: Biblioteca Fundamentos de la Construcción de Chile. Cámara Chilena de la Construcción.

Sanhueza, C. (2012). Un saber geográfico en acción. Hans Steffen y el litigio patagónico 1892-1902. Magallania, 40, 2144.

Sepúlveda, J. (1998). Francisco Hudson un marino poco conocido en nuestra historia. Revista Marina en línea, 6, 19-36.

Sociedad de Historia y Geografía de Aisén (2012). Carlos Oportus Mena antes de 1928. Disponible en http://sohigeo. wordpress.com/2012/04/04/carlos-oportus-menaantes-de-1928/

Thayer Ojeda, T. (1918). Cuestiones de Geografía Austral, Revista Chilena de Historia y Geografía, XXV (29), 161-217.

Urbina, X. (2014). Fuentes para la Historia de la Patagonia Occidental en el período colonial. Primera parte: siglos XVI y XVII. Valparaíso: Ediciones Universitarias de Valparaíso de la Pontificia Universidad Católica de Valparaíso.

Valhondo, J. (2010). Reflexiones sobre el concepto de fronteras. ETNICEX. Asociación profesional extremeña de Antropología, 1, 133-145.

Villagrán, J., Núñez, A., \& Hidalgo, R. (1997). Políticas públicas y ocupación del territorio de la XI región de Aisén. Revista de Geografía Norte Grande. Santiago, 24, 11-18.

Wodak, R. (2003). El enfoque histórico del discurso En Wodak, R; Meyer, M. (2003). Métodos de análisis crítico del discurso. Barcelona: Gedisa.

Wodak, R (2003). De qué trata el análisis crítico del discurso (ACD). Resumen de su historia, sus conceptos fundamentales y sus desarrollos. En Wodak, R; Meyer, M. (2003). Métodos de análisis crítico del discurso. Barcelona: Gedisa. 
